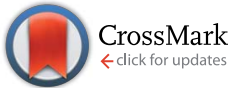

Cite this: RSC Adv., 2015, 5, 75895

Received 14th July 2015

Accepted 29th August 2015

DOI: $10.1039 / c 5 r a 13825 f$

www.rsc.org/advances

\section{A theoretical study on borenium ion affinities toward ammonia, formaldehyde and chloride anions $\dagger$}

\begin{abstract}
Milovan Stojanovića and Marija Baranac-Stojanović ${ }^{\star b}$
Various borenium ion affinities toward three ligands $\left(\mathrm{L}^{\prime}=\mathrm{NH}_{3}, \mathrm{HCHO}\right.$ and $\left.\mathrm{Cl}^{-}\right)$have been evaluated by DFT calculations in the gas-phase and in solvent $\left(\mathrm{CH}_{2} \mathrm{Cl}_{2}\right)$. The gas-phase results have been rationalized on the basis of quantitative decomposition of the total binding energy into contributions from electrostatic, orbital, dispersion and Pauli interactions, and energy needed to deform the interacting fragments from their optimal geometry to that they adopt in an adduct. Twenty six borenium cations, differing in the type of the two R/R' substituents covalently bound to the boron atom and the neutral stabilizing ligand $\mathrm{L}$, have been examined. With a few exceptions, the most important stabilizing interaction is electrostatic, more pronounced in the case of the charged ligand $\mathrm{Cl}^{-}$. Next come orbital interactions, involving the coordinate covalent bond formation, other charge transfer interactions between the cation and ligand, and polarization. Dispersion forces provide the smallest attraction, except in four complexes with long $B-L^{\prime}$ distances. We present how substituent $\left(R / R^{\prime}\right) /$ ligand $(L)$ variations affect binding enthalpies $(\Delta H)$ /energies $(\Delta E)$. Our results also show that the observed trend in the magnitudes of $\Delta H \mathrm{~s} / \Delta E \mathrm{~s}$ represents an interplay of the above mentioned (de)stabilizing energies, and can be explained by consideration of the boron-ligand distance and all charge/orbital interactions, rather than partial ones involving boron and ligand $\mathrm{L}^{\prime}$. Under solvent conditions, the $\mathrm{Cl}^{-}$affinities are drastically reduced and made very similar to $\mathrm{NH}_{3}$ affinities, but still larger than $\mathrm{HCHO}$ affinities.
\end{abstract}

\section{Introduction}

The chemistry of the three-coordinate boron cations, known as borenium ion $\mathbf{1},{ }^{\mathbf{1}}$ is characterized by their exceptional Lewis acidity arising from the intrinsic electron deficiency of boron, enhanced by an overall positive charge (Fig. 1). ${ }^{2}$ These species can be viewed as Lewis adducts of even more electrophilic di-coordinate borinium ion 2 with a Lewis base L. If another neutral ligand $\mathrm{L}^{\prime}$ binds to borenium ion $\mathbf{1}$, a four-coordinate boronium ion $\mathbf{3}$ is formed. While the majority of older reports were focused on the synthesis, characterization and gas-phase reactivity of boron cations, ${ }^{1,2 a}$ their condensed-phase reactions

${ }^{a}$ Center for Chemistry ICTM, University of Belgrade, Njegoševa 12, P.O. Box 473, 11000 Belgrade, Serbia

${ }^{b}$ Faculty of Chemistry, University of Belgrade, Studentski trg 12-16, P.O. Box 158, 11000 Belgrade, Serbia.E-mail: mbaranac@chem.bg.ac.rs

$\dagger$ Electronic supplementary information (ESI) available: Validity of theory level employed in the study, additional calculations done at the M06-2X/aug-cc-pVDZ and MP2/6-311++G(d,p) levels, influence of BSSE corrections on geometries, calculated $\mathrm{B}-\mathrm{R} / \mathrm{R}^{\prime}$ and $\mathrm{B}-\mathrm{L}$ bond lengths, NBO charges at boron atom and electron occupancies of boron's p-orbital of borenium cations 4-29, energy decomposition analysis of binding interactions in $\mathrm{BF}_{3}-\mathrm{NH}_{3}$ and $\mathrm{BCl}_{3}-\mathrm{NH}_{3}$, optimized structures of borenium cations and their adducts with $\mathrm{NH}_{3}, \mathrm{HCHO}$ and $\mathrm{Cl}^{-}$, absolute energies and $x, y, z$ coordinates of the optimized structures. See DOI: $10.1039 / \mathrm{c} 5 \mathrm{ra} 13825 \mathrm{f}$ have attracted considerable interest in recent years. Borenium ions 1 are increasingly exploited as (chiral) Lewis acid catalysts in organic synthesis ${ }^{2 b, 3}$ and as electrophilic borylation agents. ${ }^{2 b, 4}$

Although the borenium ion chemistry is based on their Lewis acidity, quantitative data that would allow one to rank a broader range of borenium species according to Lewis acidity are rather scarce. Prokofjevs ${ }^{2 \boldsymbol{b}, 5}$ calculated gas-phase ammonia affinities of a series of borenium ions, the majority of which comprised structures of synthetic interest. The results showed a wide range of $\Delta H$ values ( $\left.>50 \mathrm{kcal} \mathrm{mol}^{-1}\right),{ }^{2 b, 5}$ compared to the narrower one for neutral borane derivatives $\left(>30 \mathrm{kcal} \mathrm{mol}^{-1}\right){ }^{6}$ Solomon et al. ${ }^{4 c}$ ranked $[\mathrm{CatBNR}]^{+}\left[\mathrm{AlCl}_{4}\right]^{-}$and $\left[\left(\mathrm{CatS}_{2}\right) \mathrm{BNR}_{3}\right]^{+}\left[\mathrm{AlCl}_{4}\right]^{-}$with respect to their ability for electrophilic arene borylation and found the reactivity of $\left[\left(\mathrm{CatS}_{2}\right) \mathrm{BNR}_{3}\right]^{+}\left[\mathrm{AlCl}_{4}\right]^{-}$to lie between that of dichloro- and catecholato-boron electrophiles. The related $N, N^{\prime}$-(2,6-diisopropylphenyl)-2-bromo-1,3,2-diazaborole was resistant to halide abstraction, obviously due to steric

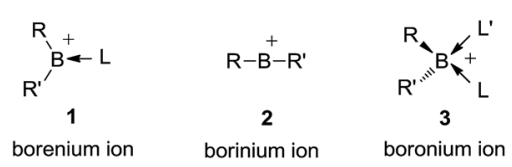

Fig. 1 Structures of borenium 1, borinium 2 and boronium 3 cations. 
hindrance. ${ }^{4 c}$ Clark et $a .^{7}$ calculated hydride anion affinities (HIAs) and chloride anion affinities (CIAs) of $\left[\mathrm{Cl}_{2} \mathrm{BL}\right]^{+}$, $[\mathrm{PhClBL}]^{+},[\mathrm{CatBL}]^{+}$and $\left[\left(\mathrm{CatS}_{2}\right) \mathrm{BL}\right]^{+}$species, where $\mathrm{L}=\mathrm{NR}_{3}$, $\mathrm{P} t \mathrm{Bu}_{3}$, pyridine and 2,6-lutidine. Although, there was a general correlation between HIAs and CIAs, a number of deviations were explained by an enhancement of relative CIAs, compared to relative HIAs, due to the increased positive charge at boron and greater steric demand of chloride compared to hydride. Replacement of catechol with chlorides resulted in a significant increase of both HIAs and CIAs. ${ }^{7}$ In an earlier work, aimed at gaining insight into the structure and bonding in boron cations, the relative $\mathrm{B}-\mathrm{L}$ bond dissociation energies in $\left[\mathrm{R}_{2} \mathrm{BL}\right]^{+}$species were calculated $\left(\mathrm{R}=\mathrm{H}, \mathrm{NH}_{2} ; \mathrm{L}=\mathrm{H}_{2} \mathrm{O}\right.$, pyridine, $\mathrm{NH}_{2} \mathrm{Me}, \mathrm{HCN}$, $\mathrm{CO}, \mathrm{PH}_{3}, \mathrm{H}_{2} \mathrm{~S}$ ). These actually correspond to the $\mathrm{L}$ affinities of borinium ions 2 and show the extent of borenium ion stabilization provided by ligand L. ${ }^{8}$ Borinium ion derived from CatBCl was estimated to be a powerful Lewis acid, having stronger affinity toward $\mathrm{Et}_{3} \mathrm{PO}$ than $\mathrm{Et}_{3} \mathrm{Si}^{+}, \mathrm{BBr}_{3}, \mathrm{AlCl}_{3}$ and $\mathrm{B}\left(\mathrm{C}_{6} \mathrm{~F}_{5}\right)_{3} \cdot{ }^{9}$

Lewis acidity of an acid is dependant on the structure of a Lewis base. Hence, we will use the term binding affinity to refer to the strength of a coordinate covalent bonding (or dative bonding) between an ion of the type 1 and a new ligand $\mathrm{L}^{\prime}$, while an intrinsic Lewis acidity can be evaluated by determination of boron's valence deficiency and is not related to the covalent bond strength. ${ }^{6}$

Due to the scarce literature data, we have performed a systematic computational study with an aim to obtain information about substituents $\left(\mathrm{R} / \mathrm{R}^{\prime}\right)$ and ligand $(\mathrm{L})$ effects on binding affinities of a series of borenium ions 1 toward a new ligand $\mathrm{L}^{\prime}$. In the first part of the work, boron cations 4-20 differing in substituents $\mathrm{R} / \mathrm{R}^{\prime}$ and having the same $\mathrm{L}=\mathrm{NH}_{3}$, were examined as model compounds (Fig. 2). Since many known and synthetically useful borenium ions are (poly)cylic systems, heteroatom substituents ( $\mathrm{N}, \mathrm{O}, \mathrm{P}$ and $\mathrm{S}$ ) were included in a five-membered ring (structures 8, 11-20). In the second part of the work, the $\mathrm{R} / \mathrm{R}^{\prime}$ moiety, chosen to be 1,3,2-oxazaborolidine heterocycle, was kept constant, while $\mathrm{L}$ was varied to include model ligands of synthetic interest such as amines $\left(\mathrm{Me}_{3} \mathrm{~N}\right)$, phosphines $\left(\mathrm{PH}_{3}, \mathrm{Me}_{3} \mathrm{P}\right)$, ethers $\left(\mathrm{Me}_{2} \mathrm{O}\right)$, thioethers $\left(\mathrm{Me}_{2} \mathrm{~S}\right)$, 2,6-lutidine (lut) and carbon-based ligands (carbenes), represented by structures 21-29. All cations were computationally tested for their binding affinities toward ammonia, formaldehyde and chloride anion, in the gas-phase and in the solvent, chosen to be $\mathrm{CH}_{2} \mathrm{Cl}_{2}$, often used in borenium-ion chemistry. Ammonia has been chosen because ammonia-borane complexes are considered as prototypes of the coordinate covalent bond. ${ }^{\mathbf{6} 10}$ Since an important synthetic application of borenium ions is their Lewis acid catalysis involving carbonyl compounds as substrates, ${ }^{2 \boldsymbol{b}, 3 \boldsymbol{f}}$ formaldehyde was selected as a model ligand to represent this type of compounds. Finally, chloride anion is often the one that has to be removed from boron atom so that borenium ion can be generated. The accessibility of borenium species has thus been estimated by evaluation of chloride anion affinities.

\section{Computational details}

All calculations have been done at the DFT level, by using the M06-2X functional ${ }^{11}$ and 6-311++G(d,p) basis set. ${ }^{12}$ The M06-2X functional has been shown to accurately model coordinate covalent bonding ${ }^{6,13}$ and was chosen for this study (see ESI $\dagger$ for more details on comparison of the chosen theory level with experimental data and previous calculations, Table $\mathrm{S} 1 ; \uparrow$ for additional calculations performed at the M06-2X/aug-cc-pVDZ ${ }^{14}$

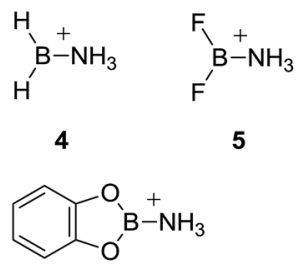

11<smiles>[NH3+][B-]1OCCS1</smiles>

16<smiles>C[As+]1BNCCO1</smiles>

21

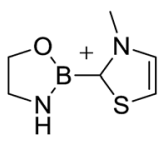

26

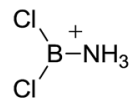

6<smiles>[NH3+][B-]1PCCS1</smiles>

12<smiles>[NH3+][B-]1NCCS1</smiles>

17<smiles>CO[B-]1NCCO1</smiles>

22

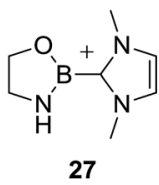

$\underset{\mathrm{H}_{3} \mathrm{C}^{\prime}}{\stackrel{\mathrm{B}-\mathrm{NH}_{3}}{\mathrm{H}_{3} \mathrm{C}^{+}}}$

7<smiles>[NH3+][B-]1OCCP1</smiles>

13<smiles>[NH3+][B-]1NCCO1</smiles>

18<smiles>C[Nb+]1BNCC1</smiles>

23<smiles>[NH3+][B-]1PCCP1</smiles>

8<smiles>C[B-]([NH-])P</smiles>

9<smiles>[NH3+][B-]1SCCS1</smiles>

14<smiles>[NH3+][B-]1NCCP1</smiles>

19<smiles>C[13CH2]B1NCCO1</smiles>

24
$\mathrm{Ph}^{\mathrm{B}-\mathrm{NH}_{3}}$

10<smiles>[NH3+][B-]1OCCO1</smiles>

15<smiles>[NH3+]B1NCCN1</smiles>

20<smiles>[PH3+]B1NCCO1</smiles>

25<smiles>CN1c2ccccc2N(C)C1[B-]1NCCO1</smiles><smiles></smiles>

Fig. 2 Structures of borenium cations examined in this work. 
and MP2/6-311++G(d,p) ${ }^{\mathbf{1 5}}$ levels for $\mathrm{NH}_{3}$-complexes of 4-8, see Table S2 in the ESI $\dagger$ and the associated discussion). All geometries were fully optimized using the Gaussian 09 program package, ${ }^{\mathbf{1 6}}$ followed by frequency calculations to find whether they correspond to energy minima (no imaginary frequencies). The G09 default geometry convergence criteria were used, that is max force $4.5 \times 10^{-4}$, RMS force $3 \times 10^{-4}$, max disp $1.8 \times$ $10^{-3}$ and RMS disp $1.2 \times 10^{-3}$, and fine integration grid. At the theory level employed, structure 4 , with shallow potential energy surface, could not be optimized as a true minima, that is, it contained an imaginary frequency: $140.23 i \mathrm{~cm}^{-1}$.

Binding enthalpies $(\Delta H)$ and binding energies $(\Delta E)$ were calculated as shown in eqn (1). Gas-phase values are corrected for the basis set superposition error (BSSE) by using the counterpoise (CP) method of Boys and Bernardi ${ }^{17}$ (for the effect of BSSE corrections on molecular geometries and thus obtained $\Delta H \mathrm{~s} / \Delta E \mathrm{~s}$, see Table $\mathrm{S} 2$ in the $\mathrm{ESI}^{\dagger}+$ and the associated discussion).

$$
\begin{aligned}
\Delta H / \Delta E= & \Delta H / \Delta E_{\text {Lewis adduct }}-\left[\Delta H / \Delta E_{\text {borenium cation }}\right. \\
& \left.+\Delta H / \Delta E_{\mathrm{L}^{\prime}}\right]
\end{aligned}
$$

The binding energy $\Delta E$ consists of two parts, deformation energy $\left(\Delta E_{\text {def }}\right)$ and interaction energy $\left(\Delta E_{\text {int }}\right)$, as shown in eqn (2):

$$
\Delta E=\Delta E_{\mathrm{def}}+\Delta E_{\mathrm{int}}
$$

When two species (cation and ligand $\mathrm{L}^{\prime}$ ) associate, their geometries change. An energy required for this change is described as deformation energy ( $\left.\Delta E_{\text {def }}\right)$, and represents energy of isolated cation and ligand $\mathrm{L}^{\prime}$ at adduct geometry minus energy of isolated cation and ligand $\mathrm{L}^{\prime}$ at their optimal geometry, eqn (3).

$$
\begin{aligned}
\Delta E_{\text {def }}= & \left(\Delta E_{\text {cation in adduct }}+\Delta E_{\mathrm{L}^{\prime} \text { in adduct }}\right) \\
& -\left(\Delta E_{\text {cation optimal }}+\Delta E_{\mathrm{L}^{\prime} \text { optimal }}\right)
\end{aligned}
$$

In the analysis, structural changes due to (partial) rehybridization of boron atom, following the complex formation, are involved in this energy term. The interaction energy $\left(\Delta E_{\text {int }}\right)$ reflects the energy of adduct formation from two deformed fragments, cation and $\mathrm{L}^{\prime}$.

To gain an insight into the nature of borenium cation-ligand interactions, the $\Delta E_{\text {int }}$ was partitioned into five energy terms (eqn (4)), by using the localized molecular orbital energy decomposition analysis (LMOEDA), developed by $\mathrm{Su}$ and $\mathrm{Li}^{18}$ and implemented into the Gamess programe package. ${ }^{\mathbf{1 9}}$

$$
\Delta E_{\mathrm{int}}=\Delta E_{\mathrm{elstat}}+\Delta E_{\mathrm{ex}}+\Delta E_{\mathrm{rep}}+\Delta E_{\mathrm{pol}}+\Delta E_{\mathrm{disp}}
$$

The electrostatic energy $\left(\Delta E_{\text {elstat }}\right)$ comprises attractive (nucleus-electron) and repulsive (nucleus-nucleus, electronelectron) forces between the two deformed fragments that adopt their position in the adduct. This energy is usually stabilizing, since attractive interactions outweigh the repulsive ones. The exchange energy $\left(\Delta E_{\text {ex }}\right)$ refers to the quantum mechanical exchange between the same-spin electrons and is simultaneously counteracted by the repulsion energy $\left(\Delta E_{\text {rep }}\right)$. Taken together, they form the exchange repulsion ${ }^{20}$ or Pauli repulsion ${ }^{21}$ of other EDA schemes. Herein, we use the sum of $\Delta E_{\text {ex }}$ and $\Delta E_{\text {rep }}$ to represent the Pauli repulsion. The polarization energy $\left(\Delta E_{\text {pol }}\right)$ is an orbital relaxation energy accounting for charge transfer (donor-acceptor interactions between occupied orbitals on one fragment with empty orbitals on the other) and polarization (empty-occupied orbital mixing within one fragment due to the presence of another fragment). Although, this energy component is denoted as $\Delta E_{\text {pol }}$ in the original reference, ${ }^{18}$ herein we will label it as $\Delta E_{\mathrm{oi}}$, to account for all orbital interactions, and refer to it as the orbital interaction energy. The dispersion energy $\left(\Delta E_{\text {disp }}\right)$ comes from mutual correlation of electrons. All interaction energy terms are also counterpoise-corrected. The EDA was done for the gas-phase conditions, as was the natural bond orbital (NBO) analysis, performed at the same theory level by using the NBO version 6.0 (ref. 22) linked to Gaussian 09.

The gas-phase optimized geometries were used for the liquid-phase calculations of $\Delta E \mathrm{~s}$. Solvent effects were taken into account by using the integral equation formalism polarizable continuum model (IEFPCM, solvent $\left.=\mathrm{CH}_{2} \mathrm{Cl}_{2}\right){ }^{23}$

\section{Results and discussion}

\section{Geometries of borenium ions 4-29}

Optimized geometries of borenium ions 4-29 are presented in Fig. S1 in the ESI. $\dagger$ The $\left[\mathrm{H}_{2} \mathrm{BNH}_{3}\right]^{+}$cation 4 possesses a quite shallow potential energy surface (PES) with respect to the $\mathrm{B}-\mathrm{N}$ bond rotation. The energy difference between the eclipsed $\left(\varphi_{\mathrm{HBNH}}=0^{\circ}\right)$ and orthogonal $\left(\varphi_{\mathrm{HBNH}}=90^{\circ}\right)$ structures, both of $C_{\mathrm{s}}$ symmetry, was less than $5 \mathrm{cal} \mathrm{mol}^{-1}$. The lowest energy structure (by $0.9 \mathrm{cal} \mathrm{mol}^{-1}$ more stable than the orthogonal one) had the $\mathrm{HBNH}$ torsional angle of $97^{\circ}$ and it was taken as a reference for estimation of adduct formation energies. Halosubstituted borenium cations 5 and $\mathbf{6}$ feature the $C_{\mathrm{s}}$ symmetry structure with one of the $\mathrm{N}-\mathrm{H}$ bonds lying perpendicularly to the $\mathrm{Hal}_{2} \mathrm{~B}$ plane. Dimethyl-substituted cation 7 has almost eclipsed $\mathrm{N}-\mathrm{H} / \mathrm{B}-\mathrm{C}$ bonds with $\varphi_{\mathrm{HNBC}}=-1.5^{\circ}$. Two of the $\mathrm{C}-\mathrm{H}$ bonds are also nearly eclipsed with the $\mathrm{B}-\mathrm{N}$ and $\mathrm{B}-\mathrm{C}$ bonds $\left(\varphi_{\mathrm{HCBN}}=12.7^{\circ}\right.$ and $\left.\varphi_{\mathrm{HCBC}}=-8.8^{\circ}\right)$. All they point into the same direction. Optimization of Me,Ph-substituted cation 9 resulted in a structure in which one of the $\mathrm{C}-\mathrm{H}$ bonds of $\mathrm{Me}$ part and one of the $\mathrm{N}-\mathrm{H}$ bonds of $\mathrm{NH}_{3}$ moiety are found almost in plane with the phenyl ring, and they point into the same direction, the $\mathrm{C}-\mathrm{H}$ bond being oriented toward the $\mathrm{Ph}$ ring. In diphenylsubstituted borenium ion 10 one of $\mathrm{N}-\mathrm{H}$ bonds forms a small diedral angle with one of the $\mathrm{B}-\mathrm{C}$ bonds $\left(\varphi_{\mathrm{HNBC}}=11.4^{\circ}\right.$, while both phenyl rings are tilted from the CBN plane by $\sim 30^{\circ}$ and $\sim 20^{\circ}$. Five-membered heterocyclic ring in borenium ions 8 $(\mathrm{P}, \mathrm{P}), 14(\mathrm{~S}, \mathrm{~S}), 16(\mathrm{O}, \mathrm{S}), 17(\mathrm{~N}, \mathrm{~S})$ and $20(\mathrm{~N}, \mathrm{~N})$ adopts a half-chair conformation, which is significantly flattened in $\mathbf{2 0}$. One of the $\mathrm{N}-\mathrm{H}$ bonds in the $\mathrm{NH}_{3}$ moiety is nearly perpendicular to the $\mathrm{RBR}^{\prime}$ plane in $8\left(\varphi=89.4^{\circ}\right), 14\left(\varphi=86.7^{\circ}\right)$ and $20\left(\varphi=89.8^{\circ}\right)$. When heteroatoms connected to boron atom differ, one of the $\mathrm{N}-\mathrm{H}$ bonds in the $\mathrm{NH}_{3}$ part is almost eclipsed with the $\mathrm{B}-\mathrm{O}_{\text {ring }}$ bond in $16\left(\varphi_{\mathrm{HNBO}}=-4^{\circ}\right)$ and $\mathrm{B}-\mathrm{N}_{\text {ring }}$ bond in $17\left(\varphi_{\mathrm{HNBN}}=\right.$ $\left.-5.1^{\circ}\right)$. The $\mathrm{N}-\mathrm{H}$ bond in the heterocycle is mostly in the $\mathrm{NBN}(\mathrm{S})$ 
plane in $17(\mathrm{~N}, \mathrm{~S})$ and $20(\mathrm{~N}, \mathrm{~N})$, which is not the case for the $\mathrm{P}-\mathrm{H}$ bond. This is consistent with stronger electron-donating ability of $\mathrm{N}$ atom compared to $\mathrm{P}$ atom. The five-membered ring in cations 12, (P,S), $13(\mathrm{P}, \mathrm{O})$ and $19(\mathrm{P}, \mathrm{N})$ exists in envelope-like conformation with the $\mathrm{C}(4)$ atom, bound to phosphorus, being out of plane of the other four atoms. The conformation around the exocyclic $\mathrm{B}-\mathrm{N}$ bond is such that one of the $\mathrm{N}-\mathrm{H}$ bonds is found nearly eclipsed with the $\mathrm{B}-\mathrm{S}_{\text {ring }}$ bond in 12, $\left(\varphi_{\mathrm{HNBS}}=-10.4^{\circ}\right), \mathrm{B}-\mathrm{O}_{\text {ring }}$ bond in $13\left(\varphi_{\mathrm{HNBO}}=-6.4^{\circ}\right)$ and $\mathrm{B}-\mathrm{N}_{\text {ring }}$ bond in $19\left(\varphi_{\mathrm{HNBN}}=-5.4^{\circ}\right)$. The heterocyclic part in cations $15(\mathrm{O}, \mathrm{O})$ and $18(\mathrm{~N}, \mathrm{O})$ is nearly planar, while one of the $\mathrm{N}-\mathrm{H}$ bonds in the $\mathrm{NH}_{3}$ group is oriented almost perpendicularly with respect to the $\mathrm{OBO}(\mathrm{N})$ plane $\left(\varphi=83.9^{\circ}\right.$ in $15, \varphi=86.2^{\circ}$ in 18). The structure of $\left[\mathrm{CatBNH}_{3}\right]^{+} \mathbf{1 1}$ possesses the $C_{\mathrm{s}}$ symmetry with one of the $\mathrm{N}-\mathrm{H}$ bonds being perpendicular to the aromatic ring.

The B-R bond lengths in symmetrically substituted heterocyclic structures decrease in the following order: $1.865 \AA$ in 8 $(\mathrm{P}, \mathrm{P})>1.766 \AA$ in $14(\mathrm{~S}, \mathrm{~S})>1.389 \AA$ in $20(\mathrm{~N}, \mathrm{~N})>1.328 \AA$ in $15(\mathrm{O}, \mathrm{O})$. If we order the heteroatoms as $\mathrm{N}, \mathrm{O}, \mathrm{S}, \mathrm{P}$ it can be said that the replacement of any of these atoms in any of the heterocyclic structure (symmetrically or unsymmetrically substituted) by the one which is left to it will lengthen the remaining B-heteroatom bond, whereas substitution of any atom by the one which is right to it will shorten the remaining B-heteroatom bond. ${ }^{24}$ The strength of the effect follows the above atomic order, that is nitrogen/phosphorus most increases/decreases the other B-heteroatom bond. For example, the $\mathrm{B}-\mathrm{P} / \mathrm{B}-\mathrm{N}$ bond is the longest/shortest in 19, 1.913/1.369 $\mathrm{A}$. The B-L bond lengths range from $1.535 \AA$ in 11 to $1.592 \AA$ in 9 . The $\mathrm{B}-\mathrm{R} / \mathrm{R}^{\prime}$ and $\mathrm{B}-\mathrm{L}$ bond lengths for all studied borenium ions are given in Table $\mathrm{S} 3$ in the ESI. $\dagger$

The 1,3,2-oxazaborolidine ring in all cations 21-29 adopts a significantly flattened half-chair conformation. One of the $\mathrm{C}-\mathrm{N}$, $\mathrm{C}-\mathrm{P}$ and $\mathrm{H}-\mathrm{P}$ bonds in $\mathrm{L}$ part of structures 23-25 is almost eclipsed with the $\mathrm{B}-\mathrm{N}_{\text {ring }}$ bond $\left(\varphi_{\mathrm{CNBN}}=-3.5^{\circ}\right.$ in $23, \varphi_{\mathrm{CPBN}}=$ $-7.8^{\circ}$ in 24 and $\varphi_{\mathrm{HPBN}}=-3^{\circ}$ in 25). In 22 , both $\mathrm{C}-\mathrm{O}$ bonds form small diedral angles with the $\mathrm{B}-\mathrm{N}_{\text {ring }}$ and $\mathrm{B}-\mathrm{O}_{\text {ring }}$ bonds $\left(\varphi_{\mathrm{COBN}}\right.$ $=5.8^{\circ}$ and $\varphi_{\mathrm{COBO}}=-14.3^{\circ}$ ), which is the result of a strong $\mathrm{O}$ to $\mathrm{B}$ electron-donation making the oxygen atom mostly $\mathrm{sp}^{2}$ hybridized. By contrast, ion 21, stabilized by $\mathrm{Me}_{2} \mathrm{~S}$, is most stable in conformation in which the $\mathrm{B}-\mathrm{O}_{\text {ring }}$ bond bisects the MeSMe angle. The two rings in carbene-stabilized structures 26 and 27 are just slightly twisted (by less than $11^{\circ}$ ). In the case of 26, the cis-ON conformation is by $1.5 \mathrm{kcal} \mathrm{mol}^{-1}$ more stable than the cis-OS one, and it was used as a reference for the complex formation energies. The carbene part in $\mathbf{2 8}$ is tilted by $31^{\circ}$ from the NBO plane of 1,3,2-oxazaborolidine moiety, while the two rings in 29 adopt a perpendicular conformation. Cartesian coordinates of all optimized structures are given in the ESI. $\dagger$

\section{Geometries of borenium ion complexes with $\mathrm{NH}_{3}, \mathrm{HCHO}$ and $\mathrm{Cl}^{-}$}

Optimized geometries of all complexes are presented in Fig. S2-S4 in the ESI. $\dagger$ In the case of $\mathrm{NH}_{3}$-complexes with 4-9, 11-20 and 23-29, one binding geometry was obtained. For those formed from 10, 21 and 22, some conformational variations may be possible, particularly around the $\mathrm{C}_{\mathrm{Ar}}-\mathrm{B}$ bond in 10. In these cases one geometry was optimized. One binding geometry was obtained for HCHO-complexes derived from cations having the same $\mathrm{R} / \mathrm{R}^{\prime}$. When $\mathrm{R} \neq \mathrm{R}^{\prime}$, two geometries, having HCHO oriented toward either substituent, were optimized. The more stable ones are discussed in this section and shown in the ESI. $\dagger$

Upon complex formation, the trigonal planar geometry around boron atom changes to, more or less, tetrahedral. The hydrogen-, halo-, methyl- and Cat-substituted ammonia adducts formed from 4-7 and $\mathbf{1 1}$ feature the $C_{2 \mathrm{v}}$ symmetry structures, while the adduct formed from Me,Ph-borenium ion 9 possesses the $C_{\mathrm{s}}$ symmetry with the B-Me bond lying in the plane of the phenyl ring. In ammonia adducts with ions having a heterocyclic ring, this ring adopts (flattened) half-chair conformation. Just one exception is complex formed from 12 $(\mathrm{P}, \mathrm{S})$, in which the heterocyclic part exists in the envelope conformation having the $\mathrm{C}(4)$ atom out of plane of the other four atoms. The structures with the same heteroatoms have the $C_{2}$ symmetry. While $\mathrm{Me}_{2} \mathrm{~S}-, \mathrm{Me}_{2} \mathrm{O}-, \mathrm{Me}_{3} \mathrm{~N}$ - and $\mathrm{Me}_{3} \mathrm{P}$-stabilized borenium cations 21-24 form Lewis complexes with ammonia, reaction of phosphine-stabilized ion 25 ends up with $\mathrm{PH}_{3}$ substitution. All carbene- and lut-stabilized ions 26-29 bind ammonia. Upon complex formation, the most drastic geometry change in a cation occurs in the case of 26 and 29. In the former, near-to-planar geometry changes to the orthogonal one having $\mathrm{NH}_{3}$ at the sulfur side of thiazole ring. The opposite happens with 29, the structure of which changes from orthogonal to wing-shaped, in order to make a place for the $\mathrm{NH}_{3}$ ligand. Otherwise, ligand approach to boron is blocked by the two ortho-methyl groups. These geometry changes are reflected in high $\Delta E_{\text {def }}$ values, as will be discussed. Geometries of 27 and 28 in an adduct are wing-shaped, due to the change in hybridization of the boron atom.

The lowest energy structures of Lewis adducts formed from hydrogen-, halo- and methyl-substituted cations 4-7 with formaldehyde (slightly) deviate from the fully symmetric ones $\left(C_{\mathrm{s}}\right)$. The COBN torsional angles amount: $\varphi_{\mathrm{COBN}}=-164.6^{\circ} \mathrm{in}$ $[4-\mathrm{HCHO}]^{+}, \varphi_{\mathrm{COBN}}=-155.8^{\circ}$ in $[5-\mathrm{HCHO}]^{+}, \varphi_{\mathrm{COBN}}=-178.5^{\circ}$ in $[6-\mathrm{HCHO}]^{+}$and $\varphi_{\mathrm{COBN}}=\sim 180^{\circ}$ in $[7-\mathrm{HCHO}]^{+}$complex. In the case of $[9-\mathrm{HCHO}]^{+}$and $[\mathbf{1 0}-\mathrm{HCHO}]^{+}$adducts, the angles are $\varphi_{\mathrm{COBN}}=155^{\circ}$ and $\varphi_{\mathrm{COBN}}=157.9^{\circ}$, respectively, with the $\mathrm{H}_{2} \mathrm{C}$-part of formaldehyde being oriented toward the phenyl ring in the former. In complex derived from $\left[\mathrm{CatBNH}_{3}\right]^{+}$ion 11, one of formaldehyde hydrogen atoms is situated above an oxygen atom from the Cat-part, having $\varphi_{\mathrm{COBN}}=-149.3^{\circ}$. In complexes formed from cations 8 and 12-17, the heterocyclic ring exists in the half-chair conformation, which is flattened in the case of 15. The COBN diedral angles amount: $\varphi_{\mathrm{COBN}}=$ $-164.9^{\circ}$ in $[8-\mathrm{HCHO}]^{+}(\mathrm{P}, \mathrm{P}), \varphi_{\mathrm{COBN}}=-155.5^{\circ}$ in $[12-\mathrm{HCHO}]^{+}$ $(\mathrm{P}, \mathrm{S}), \varphi_{\mathrm{COBN}}=-139.2^{\circ}$ in $[13-\mathrm{HCHO}]^{+}(\mathrm{P}, \mathrm{O}), \varphi_{\mathrm{COBN}}=-168.6^{\circ}$ in $[14-\mathrm{HCHO}]^{+}(\mathrm{S}, \mathrm{S}), \varphi_{\mathrm{COBN}}=-141^{\circ}$ in $[15-\mathrm{HCHO}]^{+}(\mathrm{O}, \mathrm{O}), \varphi_{\mathrm{COBN}}=$ $-142.4^{\circ}$ in $[16-\mathrm{HCHO}]^{+}(\mathrm{O}, \mathrm{S})$ and $\varphi_{\mathrm{COBN}}=-165^{\circ}$ in $[17-\mathrm{HCHO}]^{+}$ $(\mathrm{N}, \mathrm{S})$. One of formaldehyde hydrogen atoms is always oriented toward or above a ring heteroatom. When they differ, it is the more electronegative one. Optimizations of $[18-\mathrm{HCHO}]^{+}(\mathrm{O}, \mathrm{N})$ and $\left[19-\mathrm{HCHO}^{+}(\mathrm{P}, \mathrm{N})\right.$ complexes starting from different 
geometries resulted in two structures: one in which $\mathrm{HCHO}$ is hydrogen-bonded to ring and ammonia $\mathrm{NH}$ bonds in $[18-\mathrm{HCHO}]^{+}$and only ammonia $\mathrm{NH}$ bond in $[19-\mathrm{HCHO}]^{+}$, and other in which HCHO binds to boron atom. Hydrogen bonded complexes are by $4.8 \mathrm{kcal} \mathrm{mol}^{-1}$ and $5.5 \mathrm{kcal} \mathrm{mol}^{-1}$, respectively, lower in energy. In both boron-bound adducts, ring conformation is envelope with $\mathrm{C}(4)$ bound to $\mathrm{N}$ in $[18-\mathrm{HCHO}]^{+}$ and bound to $\mathrm{P}$ in $[19-\mathrm{HCHO}]^{+}$pointing out of plane. In $[18-\mathrm{HCHO}]^{+}$, formaldehyde hydrogen atom lies above the ring oxygen atom $\left(\varphi_{\mathrm{COBN}}=137^{\circ}\right)$. The $\mathrm{COBN}$ diedral angle is larger in $[19-\mathrm{HCHO}]^{+}\left(\varphi_{\mathrm{COBN}}=-172^{\circ}\right)$, the $\mathrm{HCHO}$ just slightly pointing toward the ring nitrogen atom. Cation $20(\mathrm{~N}, \mathrm{~N})$ forms only hydrogen bonded complex in which carbonyl oxygen atom orients towards the two $\mathrm{N}-\mathrm{H}$ bonds, one belonging to the heterocycle, the other to the $\mathrm{NH}_{3}$ part. The heterocyclic ring in $[21-\mathrm{HCHO}]^{+}$adduct adopts an envelope conformation with $\mathrm{C}(4)$ atom bound to $\mathrm{N}$ pointing out of plane of the other four atoms. One of the formaldehyde hydrogen atoms is placed above the ring oxygen and $\varphi_{\mathrm{COBS}}$ amounts $132.9^{\circ}$. In complexes formed from 22-25, the heterocyclic part is in the half-chair conformation, which is appreciably flattened in $[24-\mathrm{HCHO}]^{+}$. In $[22-\mathrm{HCHO}]^{+}$and $[23-\mathrm{HCHO}]^{+}$formaldehyde hydrogen atom is situated above the ring nitrogen, while in $[24-\mathrm{HCHO}]^{+}$and $[25-\mathrm{HCHO}]^{+}$it lies above the ring oxygen atom. Diedral angles are: $\varphi_{\mathrm{COBO}}=150.4^{\circ}$ in $\left[22-\mathrm{HCHO}^{+}, \varphi_{\mathrm{COBN}}=156.7^{\circ}\right.$ in $[23-\mathrm{HCHO}]^{+}, \varphi_{\mathrm{COBP}}=-147.5^{\circ}$ in $[24-\mathrm{HCHO}]^{+}$and $\varphi_{\mathrm{COBP}}=$ $-130^{\circ}$ in $[25-\mathrm{HCHO}]^{+}$. Carbene-stabilized cations 26-28 bind $\mathrm{HCHO}$ in such a way that one of its hydrogen atoms orients toward the 1,3,2-oxazaborolidine ring nitrogen in 26, and 1,3,2oxazaborolidine ring oxygen in 27 and 28, with $\varphi_{\mathrm{COBC}}=141.8^{\circ}$, $\varphi_{\mathrm{COBC}}=-134.2^{\circ}$ and $\varphi_{\mathrm{COBC}}=-117.8^{\circ}$, respectively. The 1,3,2oxazaborolidine is in flat half-chair conformation. The OBN and carbene planes form angles of $18.5^{\circ}$ in $26,21.4^{\circ}$ in 27 , and $39.7^{\circ}$ in 28. In the case of $\mathrm{HCHO}$ binding, the geometry of cation 26 does not change to the orthogonal one, as it does upon $\mathrm{NH}_{3}$ binding. This could be ascribed to the long $\mathrm{B}-\mathrm{OCH}_{2}$ distances in adducts derived from 26-28 (together with $[\mathbf{2 4 -} \mathrm{HCHO}]^{+}$, they are the longest among all complexes studied), so that HCHO does not interfere much with the original cation structure. Borenium cation 29 does not bind $\mathrm{HCHO}$ at boron atom, but forms hydrogen-bonded complex involving carbonyl oxygen and $\mathrm{NH}_{\text {ring }}$ group.

Reactions of hydrogen-, fluoro-, methyl- and Cat-substituted borenium cations 4, 5, 7 and 11 with chloride anion result in structures with the $C_{\mathrm{s}}$ symmetry. The structure formed from chloro-substituted cation 6 has the $C_{3 \mathrm{v}}$ symmetry. In the case of product obtained from $\mathrm{Me}, \mathrm{Ph}$-substituted ion $\mathbf{9}$, the Me-B bond forms small diedral angle with the phenyl ring, $\varphi_{\mathrm{CBCC}}=-15.5^{\circ}$. Products formed from $8(\mathrm{P}, \mathrm{P}), 14(\mathrm{~S}, \mathrm{~S}), 15(\mathrm{O}, \mathrm{O})$ and $17(\mathrm{~N}, \mathrm{~S})$ contain five-membered ring in half-chair conformation which is flattened in 15-Cl. The structure of the ring part in adducts obtained from $12(\mathrm{P}, \mathrm{S}), 13(\mathrm{P}, \mathrm{O}), 16(\mathrm{O}, \mathrm{S}), 18(\mathrm{O}, \mathrm{N}), 19(\mathrm{P}, \mathrm{N})$ and $20(\mathrm{~N}, \mathrm{~N})$ corresponds to envelope-like conformation with the $\mathrm{C}$ atom bound to $\mathrm{P}$ in 12, 13 and 19, and bound to $\mathrm{O}$ in 16 and 18 being out of plane. Reactions of $\mathrm{Me}_{2} \mathrm{~S}$ - and $\mathrm{H}_{3} \mathrm{P}$-stabilized cations 21 and 25 with chloride result in L substitution, while all other cations 22-24 and 26-29 form tetra-coordinated products. As in the case of the formation of ammoniacomplexes, an analogous geometry change occurs in cations 26 and 29, while 27 and 28 adopt a wing-shaped structure due to the change in boron's hybridization. Cartesian coordinates of all optimized complexes are given in the ESI. $\dagger$

\section{Binding enthalpies and energy decomposition analysis}

We first checked if there exists any correlation between the gasphase binding enthalpies $(\Delta H)$ /energies $(\Delta E)$ and the following parameters: (1) B-L' distance in a complex (given in Tables 1-4), (2) calculated NBO charge at boron atom of a borenium cation and (3) calculated electron occupancy of boron's p-orbital in a borenium cation. Values for the latter two are shown in Table S3 in the ESI. $\dagger$

The results show that $\Delta H \mathrm{~s} / \Delta E \mathrm{~s}$ are moderately correlated with the B-L' bond length having correlation coefficients of $R^{2}=$ 0.74/0.74 for $\mathrm{NH}_{3}$ complexes with cations 4-20, $R^{2}=0.88 / 0.88$ for $\mathrm{NH}_{3}$ complexes with cations 21-29, $R^{2}=0.56 / 0.57$ for HCHO complexes with 4-20, $R^{2}=0.37 / 0.35$ for $\mathrm{Cl}^{-}$adducts with 4-20 and $R^{2}=0.77 / 0.78$ for $\mathrm{Cl}^{-}$adducts with 21-29. As expected, better accommodation of a ligand (shorter B-L' bond) leads to stronger attractive interactions (nucleus-electron electrostatic attraction, orbital and dispersion interactions), but also to larger repulsive interactions (nucleus-nucleus, electron-electron electrostatic repulsion and Pauli repulsion). It is their relative magnitude (substituent-dependent) that determines the strength of cation-ligand interaction, along with energy spent for fragment deformations. There was no correlation between $\Delta H \mathrm{~s} / \Delta E \mathrm{~s}$ and $\mathrm{B}-\mathrm{O}$ distance in the case of HCHO-complexes with cations 21-29.

The $\Delta H \mathrm{~s} / \Delta E \mathrm{~s}$ did not show any correlation with the positive charge located at boron atom in borenium cations. Likewise, charges at boron do not correlate with the net electrostatic attractive energies between cation and ligand $\mathrm{L}^{\prime}$. This lack of correlation can be rationalized by taking into account the two effects: (1) distance-sensitivity of this type of interactions and (2) electrostatic forces could better be explained as an all-charge phenomenon, not as partial interactions between individual atoms or group of atoms. Therefore, these results show that electrostatic interactions between boron and ligand do not play an important role in overall binding affinity and are even not dominant electrostatic forces.

As the electron occupancy of boron's p-orbital increases, binding enthalpies/energies should decrease (become less negative), due to diminished availability of boron to accept electron density. This trend was found for complex formation between 4-20 and all examined ligands, though correlation coefficients were low: $R^{2}=0.44 / 0.45$ for $\mathrm{NH}_{3}$ complexes, $R^{2}=$ $0.47 / 0.49$ for HCHO complexes and $R^{2}=0.27 / 0.29$ for adducts with $\mathrm{Cl}^{-}$. Variations of boron's p-orbital electron occupancies due to change of $\mathrm{L}$ bound to boron in cations 21-29 did not show the correct correlation with $\Delta H \mathrm{~s} / \Delta E \mathrm{~s}$. The same stands for the orbital interaction energy $\Delta E_{\mathrm{oi}}$ of complexes and boron's p-orbital occupancies. This can be explained by taking into account the following: (1) distance-dependence of orbital interactions and (2) in addition to coordinate covalent bonding, other cation-ligand charge transfer (hyperconjugative) interactions and polarization have important contribution to total orbital interactions. 
Table 1 Calculated $\mathrm{B}-\mathrm{NH}_{3}$ distances $\left(d_{\mathrm{BN}}, \AA\right), \mathrm{NH}_{3}$ affinities $\left(\Delta H\right.$ at $298.15 \mathrm{~K}$ and $\Delta E$, values in italic are in $\left.\mathrm{CH}_{2} \mathrm{Cl}_{2}\right)$ and energy decomposition of binding interactions. ${ }^{a, b, c, d}$ All energy values are in $\mathrm{kcal} \mathrm{mol}^{-1}$

\begin{tabular}{|c|c|c|c|c|c|c|c|c|c|}
\hline Ion & $d_{\mathrm{BN}}$ & $\Delta H$ & $\Delta E$ & $\Delta E_{\text {def }}$ & $\Delta E_{\text {int }}$ & $\Delta E_{\text {elstat }}$ & $\Delta E_{\text {ex+rep }}$ & $\Delta E_{\mathrm{oi}}$ & $\Delta E_{\text {disp }}$ \\
\hline 4 & 1.613 & -54.37 & $-58.88,-53.59$ & 18.64 & -77.63 & $-96.31(45.4 \%)$ & 134.37 & $-95.14(44.9 \%)$ & $-20.55(9.7 \%)$ \\
\hline 5 & 1.618 & -49.82 & $-52.40,-49.51$ & 28.77 & -81.17 & $-108.42(46.8 \%)$ & 150.33 & $-100.22(43.3 \%)$ & $-22.86(9.9 \%)$ \\
\hline 7 & 1.640 & -36.69 & $-40.47,-38.90$ & 21.32 & -61.79 & $-98.16(46.3 \%)$ & 150.44 & $-90.66(42.7 \%)$ & $-23.41(11.0 \%)$ \\
\hline 8 & 1.621 & -33.85 & $-37.07,-40.38$ & 25.14 & -62.21 & $-115.14(46.1 \%)$ & 187.82 & $-110.72(44.3 \%)$ & $-24.17(9.6 \%)$ \\
\hline 9 & 1.638 & -32.87 & $-36.32,-37.78$ & 23.07 & -59.39 & $-103.83(46.2 \%)$ & 164.84 & $-95.72(42.6 \%)$ & $-25.13(11.2 \%)$ \\
\hline 12 & 1.627 & -28.56 & $-31.52,-34.40$ & 29.45 & -60.97 & $-115.88(46.1 \%)$ & 190.23 & $-111.17(44.3 \%)$ & $-24.15(9.6 \%)$ \\
\hline 13 & 1.643 & -26.65 & $-29.20,-30.47$ & 27.54 & -56.74 & $-106.99(46.8 \%)$ & 171.88 & $-98.38(43.0 \%)$ & $-23.25(10.2 \%)$ \\
\hline 14 & 1.625 & -26.62 & $-29.42,-32.03$ & 30.31 & -59.73 & $-120.33(46.2 \%)$ & 200.47 & $-115.69(44.5 \%)$ & $-24.18(9.3 \%)$ \\
\hline 15 & 1.639 & -26.28 & $-28.30,-27.84$ & 33.00 & -61.30 & $-105.64(47.5 \%)$ & 161.24 & $-94.41(42.4 \%)$ & $-22.49(10.1 \%)$ \\
\hline 16 & 1.638 & -26.15 & $-28.69,-30.05$ & 29.07 & -57.76 & $-111.99(47.0 \%)$ & 180.72 & $-103.16(43.3 \%)$ & $-23.33(9.7 \%)$ \\
\hline 17 & 1.653 & -18.82 & $-20.86,-20.95$ & 29.76 & -50.62 & $-110.65(47.2 \%)$ & 183.86 & $-100.84(43.0 \%)$ & $-22.99(9.8 \%)$ \\
\hline
\end{tabular}

${ }^{a}$ Calculated at the M06-2X/6-311++G(d,p)//M06-2X/6-311++G(d,p) level. ${ }^{b}$ Gas-phase association enthalpies $(\Delta H)$, energies $(\Delta E)$ and all interaction energy terms are corrected for the BSSE by using the counterpoise method. ${ }^{c} \Delta E=$ total binding energy, $\Delta E_{\text {def }}=$ deformation energy, $\Delta E_{\text {int }}=$ interaction energy, $\Delta E_{\text {elstat }}=$ electrostatic energy, $\Delta E_{\text {ex+rep }}=$ exchange repulsion energy, $\Delta E_{\mathrm{oi}}=$ orbital interaction energy, $\Delta E_{\text {disp }}=$ dispersion energy. ${ }^{d}$ Values in parentheses are percentage contribution to all attractive interactions.

Thus, the overall strength of cation-ligand interactions will be considered as an interplay of various interactions involving all atoms contained in cation and ligand $\mathrm{L}^{\prime}$, and a distance at which cation and $\mathrm{L}^{\prime}$ approach each other.

\section{Ammonia affinity of cations 4-20}

Calculated binding enthalpies $(\Delta H)$, energies $(\Delta E)$ and LMOEDA analysis of binding interactions between borenium ions 4-20 and $\mathrm{NH}_{3}$ are presented in Table 1, along with the calculated B- $\mathrm{NH}_{3}$ distances. The gas-phase results will be discussed first, followed by discussion of solvent effects on $\Delta E \mathrm{~s}$, which are presented in the last paragraph of this section.

The $\Delta H \mathrm{~s}$ range from $-54.4 \mathrm{kcal} \mathrm{mol}^{-1}$ for the strongest acceptor $4(\mathrm{H}, \mathrm{H})^{25}$ to $-12.9 \mathrm{kcal} \mathrm{mol}^{-1}$ for the weakest acceptor $20(\mathrm{~N}, \mathrm{~N})$. The $\Delta E$ s show almost the same trend as $\Delta H \mathrm{~s}$ (there are two exceptions, cations 13 and 14, and 15 and 16, for which the trend in $\Delta E \mathrm{~s}$ is the reverse to that in $\Delta H \mathrm{~s}$, though energy differences are quite small and correlation between $\Delta H \mathrm{~s}$ and $\Delta E \mathrm{~s}$ is high, $\left.R^{2}=0.999\right)$. Calculated $\mathrm{B}-\mathrm{NH}_{3}$ distances range from $1.608 \AA$ in $6(\mathrm{Cl}, \mathrm{Cl})$ to $1.667 \AA$ in 20 . As a comparison, the experimentally determined $\mathrm{B}-\mathrm{N}$ bond length in $\mathrm{BH}_{3}-\mathrm{NH}_{3}$ complex amounts 1.6576(16) $\AA .^{26}$ Deformation energy $\left(\Delta E_{\text {def }}\right)$ is the smallest for $4\left(18.6 \mathrm{kcal} \mathrm{mol}^{-1}\right)$, which is expected due to the small steric hindrance from hydrogen atoms, and the largest for $15(\mathrm{O}, \mathrm{O})\left(33 \mathrm{kcal} \mathrm{mol}^{-1}\right)$. The net stabilizing energy of a complex is determined by the relative magnitudes of deformation and interaction energies, so that $\Delta E_{\text {int }}$ do not follow exactly the same trend as $\Delta H \mathrm{~s} / \Delta E \mathrm{~s}$.

The LMOEDA shows that the nature of binding interactions is pretty much the same in complexes formed from all cations 4-20: major contributions to complex stabilization come from
$\Delta E_{\text {elstat }}(45.4 \%$ in 4 to $47.9 \%$ in 20$)$ and $\Delta E_{\text {oi }}(42 \%$ in 20 to $45.2 \%$ in 6), while $\Delta E_{\text {disp }}$ range from $9.2 \%$ in $\mathbf{1 1}$ to $11.6 \%$ in $\mathbf{1 0}$. The contributions of $\Delta E_{\text {elstat }}$ and $\Delta E_{\mathrm{oi}}$ are almost equal in $\mathbf{4}$ and $\mathbf{6}$, while in all other complexes the percentage contribution of electrostatic interactions slightly overcomes the percentage contribution of orbital interactions.

The strongest ammonia acceptor $4(\mathrm{H}, \mathrm{H}), \Delta H / \Delta E=-54.4 /$ $-58.9 \mathrm{kcal} \mathrm{mol}^{-1}$ owes its large binding affinity to the small deformation energy and large interaction energy $\left(\Delta E_{\text {int }}\right.$ is larger only in adduct formed from 5). As a comparison, the counterpoise-corrected interaction energy in $\mathrm{BH}_{3}-\mathrm{NH}_{3}$ ranges from $-39.8 \mathrm{kcal} \mathrm{mol}^{-1}$ to $-44.2 \mathrm{kcal} \mathrm{mol}^{-1}$, at various theory levels employed. ${ }^{18}$ In the case of $\left[4-\mathrm{NH}_{3}\right]^{+}$, the magnitudes of electrostatic and dispersion energies are the smallest among all complexes studied, while orbital interactions exceed those in only four ammonia adducts (formed from 7, 15, 18 and 20). This means that the large $\Delta E_{\text {int }}$ originates from the small Pauli repulsion, not from strong attractive interactions, again related to the small steric hindrance in the case of hydrogen atoms as substituents.

The $\mathrm{NH}_{3}$ affinity of 4 is followed by that of 5 (F,F), $\Delta H / \Delta E=$ $-49.8 /-52.4 \mathrm{kcal} \mathrm{mol}^{-1}$, and then by that of $6(\mathrm{Cl}, \mathrm{Cl}), \Delta H / \Delta E=$ $-44.8 /-48.2 \mathrm{kcal} \mathrm{mol}^{-1}$. Interestingly, whereas $\mathrm{BCl}_{3}$ binds ammonia more strongly than $\mathrm{BF}_{3}$ by $\Delta H / \Delta E=3.2 / 3.8 \mathrm{kcal}$ $\mathrm{mol}^{-1}$ at the employed theory level (see Tables S1 and S4 in the $\mathrm{ESI} \dagger$ and ref. 6), the order of $\mathrm{NH}_{3}$ affinities of 5 and $\mathbf{6}$ is reversed: cation 5 binds $\mathrm{NH}_{3}$ more strongly than 6 by $\Delta H / \Delta E=5 / 4.2 \mathrm{kcal}$ $\mathrm{mol}^{-1}$. The reason for this opposite trend lies in the interaction energy term, since deformation energies are almost the same in the case of the two neutral boranes (Table S4 $\dagger$ ), and slightly larger for the adduct formation from 5. As LMOEDA reveals, in both borane and borenium ion adducts with $\mathrm{NH}_{3}$ the Pauli 
repulsion is larger in the case of chloro derivatives and more so for neutral boranes. Thus, the reversed order of interaction energy $\left(\Delta E_{\text {int }}=-48.3 /-52.1 \mathrm{kcal} \mathrm{mol}^{-1}\right.$ for $\mathrm{BF}_{3}-\mathrm{NH}_{3} / \mathrm{BCl}_{3}-\mathrm{NH}_{3}$, $\Delta E_{\text {int }}=-81.2 /-75.3 \mathrm{kcal} \mathrm{mol}^{-1}$ for $\left.\left[5-\mathrm{NH}_{3}\right]^{+} /\left[6-\mathrm{NH}_{3}\right]^{+}\right)$stems from a significant increase in $\Delta E_{\text {elstat }}$ (by $13.1 \mathrm{kcal} \mathrm{mol}^{-1}$ ) and $\Delta E_{\text {oi }}$ (by $25.2 \mathrm{kcal} \mathrm{mol}^{-1}$ ) when one fluorine in $\mathrm{BF}_{3}$ is replaced with $\mathrm{NH}_{3}$. In the case of chloro-compounds, the increase in electrostatic and orbital stabilization in complexes upon one chlorine substitution in $\mathrm{BCl}_{3}$ with $\mathrm{NH}_{3}$ is much smaller, by

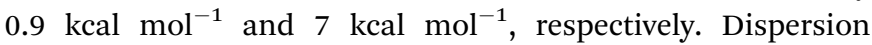
interactions practically do not change in the case of fluoro derivatives, but decrease by $1.2 \mathrm{kcal} \mathrm{mol}^{-1}$ when more polarizable chlorine is exchanged with the ammonia. It should also be noted that 5 deserves its higher affinity toward ammonia than 6 to smaller Pauli repulsion, while all attractive energy components are larger in $\left[6-\mathrm{NH}_{3}\right]^{+}$. Thus, in the case of complex formation with borenium cations, larger atoms, from the second octal row of periodic table, provide more electrostatic, orbital and dispersion stabilization and larger Pauli destabilization. This holds for other heteroatoms, too, as will be seen in further discussion.

When halogen substituents in borenium ion are substituted with two methyl groups to form 7, the affinity toward $\mathrm{NH}_{3}$ drops by $\Delta H / \Delta E=8.1 / 7.8 \mathrm{kcal} \mathrm{mol}^{-1}$, compared to 6 , and by $\Delta H / \Delta E=$ 13.1/11.9 kcal $\mathrm{mol}^{-1}$, compared to 5 . This drop is related exclusively to less favourable $\Delta E_{\text {int }}$, because $\Delta E_{\text {def }}$ decreases, too. The Pauli repulsion in $\left[7-\mathrm{NH}_{3}\right]^{+}$is almost the same as in $\left[5-\mathrm{NH}_{3}\right]^{+}$and smaller than in $\left[6-\mathrm{NH}_{3}\right]^{+}$(Table 1). Thus, the decrease in the interaction energy by $13.5 \mathrm{kcal} \mathrm{mol}^{-1}$ compared to $\left[6-\mathrm{NH}_{3}\right]^{+}$and by $19.4 \mathrm{kcal} \mathrm{mol}{ }^{-1}$ compared to $\left[5-\mathrm{NH}_{3}\right]^{+}$is connected with a decrease in electrostatic and orbital interactions. As mentioned before, electrostatic stabilization is not simply related to the charge at boron atom, which amounts 1.412, 0.566 and 1.087 for 5, 6 and 7, respectively, but to all charge interactions (attractive and repulsive) and $\mathrm{B}-\mathrm{NH}_{3}$ distance, which is longer in $\left[7-\mathrm{NH}_{3}\right]^{+}, 1.640 \AA$, compared to $1.618 \AA$ and $1.608 \AA$ in $\left[5-\mathrm{NH}_{3}\right]^{+}$and $\left[6-\mathrm{NH}_{3}\right]^{+}$, respectively, and diminishes $\Delta E_{\text {elsatat }}$. The NBO analysis shows that the electron occupancy of boron's p-orbital decreases in the order: $6(0.460 \mathrm{e})$ $>5(0.289 \mathrm{e})>7(0.167 \mathrm{e})$. Thus, the drop in the orbital interactions should be related to a decrease in covalency due to the larger $\mathrm{B}-\mathrm{NH}_{3}$ bond, smaller polarization and other cationligand hyperconjugative interactions.

Replacement of one or both methyl groups in 7 with phenyl ring to form $\mathbf{9}$ and $\mathbf{1 0}$ further decreases affinity of borenium cations toward ammonia by $\Delta H / \Delta E=3.8 / 4.2 \mathrm{kcal} \mathrm{mol}^{-1}$ and $\Delta H / \Delta E=5.8 / 6.8 \mathrm{kcal} \mathrm{mol}^{-1}$, respectively. In the case of [9$\left.\mathrm{NH}_{3}\right]^{+}$, this is related both to the increase in deformation energy (by $1.8 \mathrm{kcal} \mathrm{mol}{ }^{-1}$ with respect to $\left[7-\mathrm{NH}_{3}\right]^{+}$) and decrease in the interaction energy (by $2.4 \mathrm{kcal} \mathrm{mol}^{-1}$ compared to $\left[7-\mathrm{NH}_{3}\right]^{+}$). Major factor responsible for smaller binding affinity of $\mathbf{1 0}$ is increase in deformation energy $\left(5.9 \mathrm{kcal} \mathrm{mol}^{-1}\right.$ with respect to $\left[7-\mathrm{NH}_{3}\right]^{+}$and $4.2 \mathrm{kcal} \mathrm{mol}^{-1}$ with respect to $\left[9-\mathrm{NH}_{3}\right]^{+}$), while interaction energy drops by only $0.9 \mathrm{kcal} \mathrm{mol}^{-1}$ compared to [7- $\left.\mathrm{NH}_{3}\right]^{+}$, and is by $1.5 \mathrm{kcal} \mathrm{mol}^{-1}$ more stabilizing compared to $\left[\mathbf{9}-\mathrm{NH}_{3}\right]^{+}$. For both $\left[\mathbf{9}-\mathrm{NH}_{3}\right]^{+}$and $\left[\mathbf{1 0}-\mathrm{NH}_{3}\right]^{+}, \Delta E_{\text {int }}$ reduces solely due to the increased Pauli repulsion, while all attractive energy components become more favourable than in $\left[7-\mathrm{NH}_{3}\right]^{+}$. The increase in $\Delta E_{\mathrm{oi}}$ and $\Delta E_{\mathrm{disp}}$ partly relates to the presence of more polarizable $\pi$-electrons enhancing dispersion interactions and affecting polarization part of $\Delta E_{\text {oi }}$ more than the charge transfer interactions associated with the $\mathrm{B}-\mathrm{N}$ bond formation. For the latter, presence of one or two phenyl rings is not favourable because it decreases availability of boron's p-orbital to accept nitrogen lone pair, due to the $\pi_{\mathrm{Ph}} \rightarrow \mathrm{p}_{\mathrm{B}}$ electron donation (calculated boron's p-orbital occupancies are $0.249 \mathrm{e}$ in 9 and $0.285 \mathrm{e}$ in 10 compared to $0.167 \mathrm{e}$ in 7 ). The $\mathrm{B}-\mathrm{N}$ bond lengths in $\left[9-\mathrm{NH}_{3}\right]^{+}$and $\left[\mathbf{1 0}-\mathrm{NH}_{3}\right]^{+}$are almost equal/slightly smaller than in $\left[7-\mathrm{NH}_{3}\right]^{+}$, suggesting the presence of strong attractive forces.

In the rest of borenium cations to be discussed, boron atom is included in a heterocycle, structures 8 and 12-20, or is connected to catechol, structure 11. The strongest affinity toward $\mathrm{NH}_{3}$ is found for $8(\mathrm{P}, \mathrm{P}), \Delta H / \Delta E=-33.8 /-37.1 \mathrm{kcal} \mathrm{mol}^{-1}$, and it is even higher than that observed for $\mathrm{Me}, \mathrm{Ph}-$ and $\mathrm{Ph}, \mathrm{Ph}$ substituted cations 9 and 10. Binding affinity of 11, $\Delta H / \Delta E=$ $-29.4 /-31.7 \mathrm{kcal} \mathrm{mol}^{-1}$, is somewhat weaker than that of $\mathbf{1 0}$. Among the complexes formed from 8 and 11-20, the $\left[\mathbf{8}-\mathrm{NH}_{3}\right]^{+}$ possesses the shortest $\mathrm{B}-\mathrm{NH}_{3}$ bond length, $d_{\mathrm{BN}}=1.621 \AA$, and its formation is accompanied by the smallest deformation energy, $\Delta E_{\mathrm{def}}=25.1 \mathrm{kcal} \mathrm{mol}^{-1}$, and the largest interaction energy, $\Delta E_{\text {int }}=-62.2 \mathrm{kcal} \mathrm{mol}^{-1}$. These observations could be ascribed to the long $\mathrm{B}-\mathrm{P}$ bonds in $\mathbf{8}$, which sterically least impedes with the $\mathrm{NH}_{3}$ approach. Once the complex is formed, the Pauli repulsion becomes strong, $\Delta E_{\text {ex+rep }}=187.8 \mathrm{kcal}$ $\mathrm{mol}^{-1}$, but is significantly exceeded by very favourable $\Delta E_{\text {elstat }}=$ $-115.1 \mathrm{kcal} \mathrm{mol} \mathrm{m}^{-1}, \Delta E_{\mathrm{oi}}=-110.7 \mathrm{kcal} \mathrm{mol}^{-1}$ and $\Delta E_{\text {disp }}=$ $-24.2 \mathrm{kcal} \mathrm{mol}^{-1}$. All interaction energy components are similar or larger only in adducts derived from $6(\mathrm{Cl}, \mathrm{Cl}), 12(\mathrm{P}, \mathrm{S})$ and $14(\mathrm{~S}, \mathrm{~S})$, which have similar or shorter $\mathrm{B}-\mathrm{NH}_{3}$ bonds and both heteroatoms come from the second octal row of the periodic table. Dispersion interactions are also more prominent in $\left[\mathbf{9}-\mathrm{NH}_{3}\right]^{+}(\mathrm{Me}, \mathrm{Ph})$ and $\left[\mathbf{1 0}-\mathrm{NH}_{3}\right]^{+}(\mathrm{Ph}, \mathrm{Ph})$, having polarizable $\pi$-electrons, than in $\left[\mathbf{8}-\mathrm{NH}_{3}\right]^{+}$. In addition, $\left[\mathbf{1 1}-\mathrm{NH}_{3}\right]^{+}$shows similar Pauli repulsion as $\left[\mathbf{8}-\mathrm{NH}_{3}\right]^{+}$, slightly stronger electrostatic stabilization, but somewhat weaker orbital and dispersion interactions. This results in $1.2 \mathrm{kcal} \mathrm{mol}^{-1}$ smaller $\Delta E_{\text {int }}$ compared to that in $\left[\mathbf{8}-\mathrm{NH}_{3}\right]^{+}$. Deformation energy accompanying the formation of $\left[11-\mathrm{NH}_{3}\right]^{+}$is by $4.2 \mathrm{kcal} \mathrm{mol}^{-1}$ higher than that needed for the formation of $\left[8-\mathrm{NH}_{3}\right]^{+}$, so that both energy terms lead to lower association energy in the case of $\left[\mathrm{CatBNH}_{3}\right]^{+}$. As the major part of deformation energy relates to geometry change of a cation, bending of the exocyclic $\mathrm{B}-\mathrm{N}$ bond in the aromatic $\mathbf{1 1}$ is energetically more costly than the same change in 8, which is the main structural change in these two cations. Even more energy is spent to deform cation 15, having two oxygen atoms connected to boron, like 11. In fact, $\Delta E_{\mathrm{def}}=$ $33 \mathrm{kcal} \mathrm{mol}{ }^{-1}$ needed for the formation of $\left[\mathbf{1 5}-\mathrm{NH}_{3}\right]^{+}$is the highest one in Table 1 and has to be ascribed to a significant ring puckering occurring during the cation- $\mathrm{NH}_{3}$ association, along with the $\mathrm{B}-\mathrm{N}$ bond bending. The reason why 15 is weaker $\mathrm{NH}_{3}$ acceptor than 11 is solely its high $\Delta E_{\text {def }}$, while $\Delta E_{\text {int }}$ are almost equal in the formation of both complexes. This somewhat contrasts with our intuitive prediction that $\mathbf{1 1}$ would be a weaker lone pair acceptor, because boron's p-orbital in it is part 
of the aromatic $10 \pi$-electron system. Even so, orbital interaction energy is more stabilizing in $\left[\mathbf{1 1}-\mathrm{NH}_{3}\right]^{+}$than in $\left[\mathbf{1 5}-\mathrm{NH}_{3}\right]^{+}$, resulting from slightly shorter $\mathrm{B}-\mathrm{N}$ distance and polarization part of orbital interactions. In addition, electrostatic energy is by the similar magnitude more stabilizing in $\left[\mathbf{1 1}-\mathrm{NH}_{3}\right]^{+}$, but Pauli repulsion is smaller in $\left[\mathbf{1 1}-\mathrm{NH}_{3}\right]^{+}$.

In fact, cations 13-16 have very similar $\mathrm{NH}_{3}$ affinities, $\Delta H=$ $-26.4 \pm 0.2 \mathrm{kcal} \mathrm{mol}^{-1}$, and are followed by the group of three cations, 17-19, the affinities of which amount $\Delta H=-18.5 \pm$ $0.3 \mathrm{kcal} \mathrm{mol}^{-1}$. The weakest ammonia acceptor is $20(\mathrm{~N}, \mathrm{~N}), \Delta H$ $=-12.9 \mathrm{kcal} \mathrm{mol}^{-1}$. All these enthalpies are exceeded by that of $12(\mathrm{P}, \mathrm{S}), \Delta H=-28.6 \mathrm{kcal} \mathrm{mol}^{-1}$. The strongest affinity of 12, among 12-20, owes to the relatively low $\Delta E_{\text {def }}$ and high $\Delta E_{\text {int }}$, the latter exceeded by only $\left[\mathbf{1 5}-\mathrm{NH}_{3}\right]^{+}$just because of smaller Pauli repulsion. Therefore, the $\mathrm{P}, \mathrm{S}$ heteroatom combination in 12 lowers association enthalpy compared to the P,P heteroatom combination in $\mathbf{8}$, but leads to somewhat larger ammonia affinity with respect to all other combinations involving $\mathrm{P}, \mathrm{S}$ and O. This is the result of relative magnitudes of $\Delta E_{\text {def }}$ and $\Delta E_{\text {int }}$, and could not be ascribed to any particular interaction. Weak ammonia affinities of nitrogen-containing heterocyclic cations 17-20 certainly come from a decrease in the interaction energy, which does not exceed $-54 \mathrm{kcal} \mathrm{mol}^{-1}$, while deformation energy values compare with those of other heterocycle-containing cations. Small magnitudes of $\Delta E_{\text {int }}$ are a consequence of long B- $\mathrm{NH}_{3}$ distances (the longest among all $\mathrm{NH}_{3}$-complexes studied) and a change in individual energy components affected by the type of atoms involved in a heterocycle. The reason why 17-20 keep the $\mathrm{NH}_{3}$ ligand at the longest distance could be a combination of good electron-donating ability of nitrogen which increases boron's p-orbital electron occupancy and steric hindrance due to the short B- $\mathrm{N}_{\text {ring }}$ bonds. Although, it should be noted that electrostatic and orbital interaction energies in some of adducts formed from 17-20 are larger than in those obtained from nitrogen-lacking heterocyclic structures and boron's p-orbital occupancy is not the highest. Here, again, elements from the second octal row ( $\mathrm{S}$ and $\mathrm{P}$ ) provide more electrostatic and orbital stabilization, and larger Pauli repulsion, more pronounced for $\mathrm{S}$ than for $\mathrm{P}$. This is evident when comparing interaction energy components in adducts derived from 17-19, which all have (almost) the same B-N distances.

When comparison between related heterocycles is made, the following can be said. The replacement of oxygen by nitrogen, that is $13(\mathrm{P}, \mathrm{O}) \rightarrow 19(\mathrm{P}, \mathrm{N}), \mathbf{1 5}(\mathrm{O}, \mathrm{O}) \rightarrow 18(\mathrm{O}, \mathrm{N})$ and $16(\mathrm{~S}, \mathrm{O}) \rightarrow$ $17(\mathrm{~S}, \mathrm{~N})$, affects mainly the Pauli repulsion upon complex formation which increases by 3.1-5.7 $\mathrm{kcal} \mathrm{mol}^{-1}$ and orbital interaction energy which decreases by $1.5-2.3 \mathrm{kcal} \mathrm{mol}^{-1}$. In addition to a slight increase in the $\mathrm{B}-\mathrm{NH}_{3}$ distance by 0.012-0.015 Å, which inherently decreases interaction energy components, the drop in $\Delta E_{\mathrm{oi}}$ is consistent with nitrogen's better electron-donating ability with respect to oxygen (also see electron occupancy values in Table S3 $\dagger$ ). The $\Delta E_{\text {elstat }}$ and $\Delta E_{\text {disp }}$ are less affected by $\mathrm{O}$ to $\mathrm{N}$ replacement, and both decrease by 0.6-1.3 kcal mol $\mathrm{kn}^{-1}$ and $0.2-0.4 \mathrm{kcal} \mathrm{mol}^{-1}$, respectively. Due to increase in repulsive energy and decrease in attractive energy, interaction energy becomes weaker, while binding enthalpies drop by $7.3-8.4 \mathrm{kcal} \mathrm{mol}^{-1}$ (also modulated by $\Delta E_{\text {def }}$ ). More drastic changes in various interaction energy components occur when sulfur is substituted with nitrogen, that is $12(\mathrm{P}, \mathrm{S}) \rightarrow 19$ $(\mathrm{P}, \mathrm{N}), 14(\mathrm{~S}, \mathrm{~S}) \rightarrow 17(\mathrm{~N}, \mathrm{~S})$ and $16(\mathrm{O}, \mathrm{S}) \rightarrow 18(\mathrm{O}, \mathrm{N})$. All interaction energy components decrease: $\Delta E_{\text {elstat }}$ by $6.9-9.7 \mathrm{kcal}$ $\mathrm{mol}^{-1}, \Delta E_{\text {oi }}$ by $10.3-14.8 \mathrm{kcal} \mathrm{mol}^{-1}, \Delta E_{\text {disp }}$ by $1.1-1.3 \mathrm{kcal}$ $\mathrm{mol}^{-1}$ and $\Delta E_{\text {ex+rep }}$ by $13.8-16.6$. Since decrease in attractive energy exceeds decrease in repulsive energy, overall interaction energy decreases. More importantly from experimental point of view, $\mathrm{S}$ to $\mathrm{N}$ substitution weakens binding enthalpies by 7.4-10.3 kcal mol ${ }^{-1}$. In fact, both $\mathrm{O} \rightarrow \mathrm{N}$ and $\mathrm{S} \rightarrow \mathrm{N}$ substitutions lead to a similar decrease in binding enthalpies. Sulfur to oxygen exchange has much smaller effect on binding enthalpies, which decrease by 0.1-1.9 kcal mol${ }^{-1}$ for the changes $12(\mathrm{P}, \mathrm{S}) \rightarrow 13(\mathrm{P}, \mathrm{O}), 14(\mathrm{~S}, \mathrm{~S}) \rightarrow 16(\mathrm{~S}, \mathrm{O})$ and $17(\mathrm{~N}, \mathrm{~S}) \rightarrow$ 18 (N,O), or increase by $0.1 \mathrm{kcal} \mathrm{mol}^{-1}$ for $16(\mathrm{O}, \mathrm{S}) \rightarrow 15(\mathrm{O}, \mathrm{O})$. Apart from any change in $8(\mathrm{P}, \mathrm{P})$, phosphorus exchange with oxygen or sulfur has a smaller effect on binding enthalpies (not exceeding $2.4 \mathrm{kcal} \mathrm{mol}^{-1}$ ), while its substitution with nitrogen, that is $12(\mathrm{P}, \mathrm{S}) \rightarrow \mathbf{1 7}(\mathrm{N}, \mathrm{S})$ and $13(\mathrm{P}, \mathrm{O}) \rightarrow \mathbf{1 8}(\mathrm{N}, \mathrm{O})$, diminishes enthalpy values by $8.4-9.7 \mathrm{kcal} \mathrm{mol}^{-1}$. Introduction of nitrogen instead of $\mathrm{S}, \mathrm{O}$ and $\mathrm{P}$ in 17-19 to form 20, decreases $\mathrm{NH}_{3}$ association enthalpies by $5.4-6 \mathrm{kcal} \mathrm{mol}^{-1}$. The weakest affinity of $20(\mathrm{~N}, \mathrm{~N})$ mainly originates from relatively low electrostatic stabilization and the weakest orbital interaction energy, making $\Delta E_{\text {int }}$ the least favourable.

Inclusion of solvent into calculations either decrease or increase binding energies. For majority of cations, the effect does not exceed $3.3 \mathrm{kcal} \mathrm{mol}^{-1}$. The largest decrease in $\Delta E$ is observed for $4,5.3 \mathrm{kcal} \mathrm{mol}^{-1}$. The above mentioned three cationic groups with similar $\Delta E$ s can still be discerned: 20 as the poorest $\mathrm{NH}_{3}$ acceptor $\left(\Delta E=13.6 \mathrm{kcal} \mathrm{mol}^{-1}\right)$, 17-19 having larger acceptor abilities $\left(\Delta E \sim 20 \mathrm{kcal} \mathrm{mol}^{-1}\right)$ and the third group now involves cations 11-16, the $\Delta E$ s of which are around $30 \mathrm{kcal} \mathrm{mol}^{-1}$. In solvent conditions, 8 (P,P) binds $\mathrm{NH}_{3}$ somewhat stronger than 7 (Me,Me) by $1.5 \mathrm{kcal} \mathrm{mol}^{-1}$, and 5 (F,F) appears to be a poorer acceptor than $6(\mathrm{Cl}, \mathrm{Cl})$, though the difference in binding energies is small $\left(0.6 \mathrm{kcal} \mathrm{mol}^{-1}\right)$.

\section{Formaldehyde affinity of cations 4-20}

Calculated binding enthalpies $(\Delta H)$, energies $(\Delta E)$ and LMOEDA analysis of binding interactions between borenium ions 4-20 and $\mathrm{HCHO}$ are given in Table 2, along with the calculated B- $\mathrm{OCH}_{2}$ distances. Discussion of the gas-phase results is followed by discussion of solvent effects, which is given in the last paragraph of this section.

In this case, $\Delta H \mathrm{~s} / \Delta E \mathrm{~s}$ span a somewhat narrower range from $-40.5 /-44.6 \mathrm{kcal} \mathrm{mol}^{-1}$ for $4(\mathrm{H}, \mathrm{H})$ to $-9.2 /-10.7 \mathrm{kcal} \mathrm{mol}^{-1}$ for $17(\mathrm{~N}, \mathrm{~S})$. Magnitudes of all $\mathrm{HCHO}$ association enthalpies are smaller than the corresponding $\mathrm{NH}_{3}$ binding enthalpies by 7.8-14 kcal $\mathrm{mol}^{-1}$, which should be ascribed to the $\mathrm{sp}^{2}$ hybridized oxygen lone pair being poorer electron donor than ammonia lone pair. $\Delta H \mathrm{~s}$ and $\Delta E \mathrm{~s}$ follow the same trend $\left(R^{2}=\right.$ 0.998) which, with few exceptions, match that for $\mathrm{NH}_{3}$ affinity. Differences in affinities toward $\mathrm{NH}_{3}$ and $\mathrm{HCHO}$ are the following: (1) cation 14 is slightly weaker $\mathrm{HCHO}$ acceptor than cations 15 and 16 by 1.4 and $0.5 \mathrm{kcal} \mathrm{mol}^{-1}$, respectively; (2) 
Table 2 Calculated $\mathrm{B}-\mathrm{OCH}_{2}$ distances $\left(d_{\mathrm{BO}}, \AA\right), \mathrm{HCHO}$ affinities $\left(\Delta H\right.$ at $298.15 \mathrm{~K}$ and $\Delta E$, values in italic are in $\left.\mathrm{CH}_{2} \mathrm{Cl}_{2}\right)$ and energy decomposition of binding interactions. ${ }^{a, b, c, d}$ All energy values are in $\mathrm{kcal} \mathrm{mol}^{-1}$

\begin{tabular}{|c|c|c|c|c|c|c|c|c|c|}
\hline Ion & $d_{\mathrm{BO}}$ & $\Delta H$ & $\Delta E$ & $\Delta E_{\mathrm{def}}$ & $\Delta E_{\text {int }}$ & $\Delta E_{\text {elstat }}$ & $\Delta E_{\text {ex+rep }}$ & $\Delta E_{\mathrm{oi}}$ & $\Delta E_{\text {disp }}$ \\
\hline 4 & 1.576 & -40.53 & $-44.59,-33.60$ & 15.14 & -59.73 & $-73.14(42.5 \%)$ & 112.51 & $-79.22(46.0 \%)$ & $-19.88(11.5 \%)$ \\
\hline 5 & 1.593 & -37.25 & $-39.40,-30.08$ & 22.70 & -62.10 & $-80.58(43.3 \%)$ & 124.04 & $-82.98(44.6 \%)$ & $-22.58(12.1 \%)$ \\
\hline 7 & 1.633 & -25.26 & $-28.06,-21.04$ & 16.26 & -44.32 & $-71.24(43.5 \%)$ & 119.43 & $-69.45(42.4 \%)$ & $-23.00(14.1 \%)$ \\
\hline 8 & 1.563 & -22.79 & $-25.05,-21.37$ & 23.05 & -48.10 & $-97.23(43.8 \%)$ & 173.73 & $-99.38(44.8 \%)$ & $-25.22(11.4 \%)$ \\
\hline 9 & 1.636 & -22.14 & $-25.07,-20.56$ & 17.96 & -43.03 & $-77.33(44.2 \%)$ & 131.89 & $-72.26(41.3 \%)$ & $-25.33(14.5)$ \\
\hline 12 & 1.601 & -18.47 & $-20.66,-17.34$ & 23.66 & -44.32 & $-91.54(44.2 \%)$ & 162.58 & $-90.67(43.8 \%)$ & $-24.69(12.0 \%)$ \\
\hline 13 & 1.626 & -17.94 & $-19.81,-15.94$ & 21.92 & -41.73 & $-81.57(44.5 \%)$ & 141.69 & $-78.01(42.5 \%)$ & $-23.84(13.0 \%)$ \\
\hline 15 & 1.682 & -15.94 & $-17.53,-11.83$ & 20.91 & -38.44 & $-70.87(45.3 \%)$ & 117.98 & $-63.59(40.7 \%)$ & $-21.96(14.0 \%)$ \\
\hline 16 & 1.632 & -15.03 & $-16.85,-12.75$ & 24.07 & -40.92 & $-83.44(44.8 \%)$ & 145.46 & $-79.56(42.7 \%)$ & $-23.38(12.5 \%)$ \\
\hline 14 & 1.628 & -14.54 & $-16.67,-12.68$ & 23.98 & -40.65 & $-90.34(44.7 \%)$ & 161.45 & $-87.54(43.3 \%)$ & $-24.22(12.0 \%)$ \\
\hline 18 & 1.754 & -10.95 & $-12.28,-5.62$ & 17.07 & -29.35 & $-64.18(46.5 \%)$ & 108.64 & $-52.84(38.3 \%)$ & $-20.97(15.2 \%)$ \\
\hline
\end{tabular}

${ }^{a}$ Calculated at the M06-2X/6-311++G(d,p)//M06-2X/6-311++G(d,p) level. ${ }^{b}$ Gas-phase association enthalpies $(\Delta H)$, energies $(\Delta E)$ and all interaction energy terms are corrected for the BSSE by using the counterpoise method. ${ }^{c}$ Labeling of all energy terms is the same as in Table $1 .{ }^{d}$ Values in parentheses are percentage contribution to all attractive interactions.

cation $\mathbf{1 7}$ is slightly weaker $\mathrm{HCHO}$ acceptor compared to $\mathbf{1 8}$ and 19 by 1.8 and $0.05 \mathrm{kcal} \mathrm{mol}^{-1}$, respectively. Calculated distances between boron and carbonyl oxygen atom of $\mathrm{HCHO}$ range from $1.563 \AA$ in $8(\mathrm{P}, \mathrm{P})$ to $1.754 \AA$ in $18(\mathrm{~N}, \mathrm{O})$. Deformation energy $\left(\Delta E_{\mathrm{def}}\right)$ is the smallest for complex formation from $4\left(15.1 \mathrm{kcal} \mathrm{mol}^{-1}\right)$ and the largest for complex formation from $16\left(24.1 \mathrm{kcal} \mathrm{mol}^{-1}\right)$. All $\Delta E_{\text {def }}$ and $\Delta E_{\text {int }}$ values are smaller than those in the corresponding ammonia complexes. Like in $\mathrm{NH}_{3}$-adducts, $\Delta E_{\text {int }}$ do not follow the same trend as $\Delta H \mathrm{~s}$ and $\Delta E \mathrm{~s}$, since the latter two are influenced by deformation energies, as well.

The LMOEDA shows that in the case of adducts formed from 4-6 and 8 the percentage contribution of the orbital interaction energy $\left(\Delta E_{\mathrm{o} i}: 44.6-46 \%\right)$ slightly prevails over the electrostatic interaction energy ( $\left.\Delta E_{\text {elstat }}: 42.5-43.8 \%\right)$, while for all other complexes contribution of electrostatic stabilization $\left(\Delta E_{\text {elstat }}\right.$ : $43.5-46.5 \%)$ is slightly more pronounced than that of orbital interaction energy $\left(\Delta E_{\mathrm{oi}}: 38.3-43.8 \%\right)$. The role of dispersion interactions in complex stabilization is slightly increased (11.4-15.2\%) compared to cation- $\mathrm{NH}_{3}$ complexes (9.2-11.6\%), which is possibly due to the presence of more polarizable $\pi$-electrons in the ligand ( $\mathrm{HCHO}$ ).

Cation 4, again, exhibits the strongest tendency to bind the ligand (HCHO), $\Delta H / \Delta E=-40.5 /-44.6 \mathrm{kcal} \mathrm{mol}^{-1}$, which stems from small $\Delta E_{\text {def }}=15.1 \mathrm{kcal} \mathrm{mol}^{-1}$ and large $\Delta E_{\text {int }}=-59.7 \mathrm{kcal}$ $\mathrm{mol}^{-1}\left(\Delta E_{\text {int }}\right.$ is larger only in adduct formed from $\mathbf{5}$, which is similar to $\mathrm{NH}_{3}$-complexes). The $\Delta E_{\text {int }}$ owes to the small Pauli repulsion, but also to the $\Delta E_{\mathrm{oi}}$ component, while $\Delta E_{\text {elstat }}$ exceeds values in just four other complexes formed from 7 (Me,Me), 15 $(\mathrm{O}, \mathrm{O}), 18(\mathrm{~N}, \mathrm{O})$ and $19(\mathrm{P}, \mathrm{N})$. This differs from ammoniaadducts where electrostatic stabilization was the smallest in the case of $\left[4-\mathrm{NH}_{3}\right]^{+}$and can be partly rationalized by the long $\mathrm{B}-\mathrm{O}$ bonds in the $\mathrm{HCHO}-a d d u c t s ~ d e r i v e d ~ f r o m ~ 7,15,18$ and 19, $d_{\mathrm{BO}}=1.633-1.754 \AA$ compared to $1.576 \AA$ in $[4-\mathrm{HCHO}]^{+}$, which diminishes charge interactions. In the case of $\mathrm{NH}_{3}$-adducts, orbital interaction energy in $\left[4-\mathrm{NH}_{3}\right]^{+}$was among the weakest ones. However, in $[4-\mathrm{HCHO}]^{+}, \Delta E_{\mathrm{oi}}=-79.2 \mathrm{kcal} \mathrm{mol}^{-1}$ exceeds values in many other HCHO-complexes and is approximately in the middle between the highest and the lowest values, $\Delta E_{\mathrm{pol}}=$ -99.4 in $[8-\mathrm{HCHO}]^{+}$and $-52.8 \mathrm{kcal} \mathrm{mol}^{-1}$ in $[18-\mathrm{HCHO}]^{+}$, respectively. This, again, could be ascribed to $\mathrm{B}-\mathrm{O}$ distances which are more lengthened in $\mathrm{HCHO}-$ complexes than in $\mathrm{NH}_{3}$ complexes with respect to $\mathrm{B}-\mathrm{O}$ and $\mathrm{B}-\mathrm{N}$ bonds in $[4-\mathrm{HCHO}]^{+}$ and $\left[4-\mathrm{NH}_{3}\right]^{+}$.

The HCHO affinity of $5(\mathrm{~F}, \mathrm{~F}), \Delta H / \Delta E=-37.2 /-39.4 \mathrm{kcal}$ $\mathrm{mol}^{-1}$, is larger than that of $\mathbf{6}(\mathrm{Cl}, \mathrm{Cl}), \Delta H / \Delta E=-30.9 /-33.3 \mathrm{kcal}$ $\mathrm{mol}^{-1}$, because of the more favourable $\Delta E_{\text {int }}$ (by $5.9 \mathrm{kcal} \mathrm{mol}^{-1}$ ), while $\Delta E_{\text {def }}$ is smaller by only $0.2 \mathrm{kcal} \mathrm{mol}^{-1}$. Like in $\mathrm{NH}_{3}$ complexes, it is the lower Pauli repulsion which is responsible for the larger $\Delta E_{\text {int }}$ in [5-HCHO $]^{+}$compared to [6-HCHO $]^{+}$, while all attractive energy terms are more stabilizing in the latter.

The effect of methyl and phenyl substituents on HCHO affinity of cations $7(\mathrm{Me}, \mathrm{Me}), \mathbf{9}(\mathrm{Me}, \mathrm{Ph})$ and $\mathbf{1 0}(\mathrm{Ph}, \mathrm{Ph})$ is the same as their influence on $\mathrm{NH}_{3}$ affinity and can be rationalized in a similar way as already discussed in the preceding section, where it was compared to halo-substituted cations. If compared with $4(\mathrm{H}, \mathrm{H})$, the replacement of hydrogen atoms by two methyl groups decreases affinity toward HCHO mainly due to the interaction energy, which decreases by $15.4 \mathrm{kcal} \mathrm{mol}^{-1}\left(\Delta E_{\text {def }}\right.$ rises by only $1.1 \mathrm{kcal} \mathrm{mol}^{-1}$ ). The drop in the $\Delta E_{\text {int }}$ has to be attributed to the increased Pauli repulsion and much more to the decreased orbital interactions, which together reduce $\Delta E_{\text {int }}$ by $16.7 \mathrm{kcal} \mathrm{mol}^{-1}$ (the net effect of $\Delta E_{\text {elstat }}$ and $\Delta E_{\text {disp }}$ is stabilization by $1.2 \mathrm{kcal} \mathrm{mol}^{-1}$, the former/latter becoming less/ more stabilizing). A decrease in $\Delta E_{\mathrm{oi}}$ can be ascribed to $\sigma_{\mathrm{CH}} \rightarrow$ $\mathrm{p}_{\mathrm{B}}$ hyperconjugation which enhances boron's p-orbital occupancy to $0.167 \mathrm{e}$ compared to only $0.023 \mathrm{e}$ in 4 , resulting in smaller coordinate covalent bond strength and longer boronligand distance (also affected by steric hindrance from methyl 
groups). The latter, in turn, reduces polarization, which should actually increase upon hydrogens substitution with methyl groups. Further substitution of one methyl group in 7 with phenyl group to form 9 decreases binding affinity by $\Delta H / \Delta E=$ $3.1 / 3 \mathrm{kcal} \mathrm{mol}^{-1}$ due to somewhat larger deformation of interacting fragments and less stabilizing $\Delta E_{\text {int }}$. The latter is made less favourable solely due to the increase in the Pauli repulsion. Replacement of another methyl by phenyl group to give $\mathbf{1 0}$ decreases HCHO affinity exclusively due to increase in the $\Delta E_{\text {def }}$, while enhancement of all attractive energy components makes the $\Delta E_{\text {int }}$ slightly more favourable with respect to that in $[7-\mathrm{HCHO}]^{+}$and $[\mathbf{9}-\mathrm{HCHO}]^{+}$.

Among the heterocycle-containing cations 8 and 11-19, high binding affinity of $8(\mathrm{P}, \mathrm{P}), \Delta H / \Delta E=-22.8 /-25.1 \mathrm{kcal} \mathrm{mol}^{-1}$, owes to the favourable interaction energy which partly results from the very short B-O bond. This is the shortest $\mathrm{B}-\mathrm{O}$ bond among all HCHO-complexes studied and can be explained in the same way as for $\mathrm{NH}_{3}$-complexes. Thus, due to the long $\mathrm{B}-\mathrm{P}$ bonds in 8, ligand approach is sterically least impeded. In the complex, all interaction energy terms, attractive $\left(\Delta E_{\text {elstat }}, \Delta E_{\text {oi }}\right.$ and $\left.\Delta E_{\text {disp }}\right)$ and repulsive $\left(\Delta E_{\text {ex }+ \text { rep }}\right)$, are the strongest, compared to all other complexes. Their net result is very favourable $\Delta E_{\text {int }}$, being stronger in just three other complexes obtained from 4-6.

While $\left.[\mathrm{CatBNH}]_{3}\right]^{+} \mathbf{1 1}$ showed the highest affinity toward $\mathrm{NH}_{3}$ among heterocyclic cations 11-20 mostly due to the favourable interaction energy (Table 1), its high affinity for HCHO comes from small deformation energy which is amongst the smallest ones of all cations 4-19 $\left(\Delta E_{\mathrm{def}} \text { in [11-HCHO }\right]^{+}$exceeds $\Delta E_{\mathrm{def}}$ in just three other adducts formed from $4(\mathrm{H}, \mathrm{H}), 7(\mathrm{Me}, \mathrm{Me})$ and 18 $(\mathrm{N}, \mathrm{O})$ ). Thus, binding of HCHO to $\mathbf{1 1}$ is accompanied by the smaller $\mathrm{B}-\mathrm{N}$ bond bending than binding of the more nucleophilic $\mathrm{NH}_{3}$ (see previous section). The $\Delta E_{\text {int }}$ in $[\mathbf{1 1}-\mathrm{HCHO}]^{+}$is not large and exceeds $\Delta E_{\text {int }}$ only in adducts obtained from nitrogen-containing heterocyclic cations 17-19. Magnitudes of $\Delta E_{\text {int }}$ and $\Delta E_{\text {def }}$ are obviously a consequence of the relatively long B-OCH $\mathrm{H}_{2}$ distance. As in the case of $\mathrm{NH}_{3}$-complexes, smaller affinity of $15(\mathrm{O}, \mathrm{O})$ toward $\mathrm{HCHO}$ compared to $\mathbf{1 1}$ comes from an increase in the 1,3,2-dioxaborolidine ring puckering and $\mathrm{B}-\mathrm{N}$ bond bending in the former, leading to higher deformation energy. Interaction energies in the two adducts are the same, despite the longer $\mathrm{B}-\mathrm{O}$ bond in $[\mathbf{1 5}-\mathrm{HCHO}]^{+}$by $0.024 \AA$ (in the case of $\mathrm{NH}_{3}$-complexes, the $\mathrm{B}-\mathrm{N}$ bond in $\left[\mathbf{1 5}-\mathrm{NH}_{3}\right]^{+}$is also longer than in $\left[11-\mathrm{NH}_{3}\right]^{+}$, but the difference is smaller, $0.011 \AA$ ). The reason why interaction energies are almost the same in adducts formed from $\mathbf{1 1}$ and $\mathbf{1 5}$ is not larger attraction in the case of 15, but smaller Pauli repulsion.

Unlike the case of $\mathrm{NH}_{3}$ as ligand, cations 12-16, containing $\mathrm{P}, \mathrm{O}$ and $\mathrm{S}$ as heteroatoms, are poorer $\mathrm{HCHO}$ acceptors than $\mathbf{1 1}$ due to the larger geometry changes associated with the complex formation, while the interaction energy is similar or higher than that in $[11-\mathrm{HCHO}]^{+}$.

The trend in HCHO affinities of 12-19 differs somewhat from that found for $\mathrm{NH}_{3}$ affinities. Whereas in the case of the latter, two cation groups, having very similar affinities within each, could be identified, the HCHO accepting ability continually decreases in the order: $12(\mathrm{P}, \mathrm{S})>13(\mathrm{P}, \mathrm{O})>15(\mathrm{O}, \mathrm{O})>16$ $(\mathrm{S}, \mathrm{O})>14(\mathrm{~S}, \mathrm{~S})>18(\mathrm{O}, \mathrm{N})>19(\mathrm{P}, \mathrm{N})>17(\mathrm{~N}, \mathrm{~S})$ and represents a balance between $\Delta E_{\text {def }}$ and $\Delta E_{\text {int }}$. Compared to $8(\mathrm{P}, \mathrm{P})$, cation 12 $(\mathrm{P}, \mathrm{S})$ shows weaker $\mathrm{HCHO}$ affinity by $4.3 \mathrm{kcal} \mathrm{mol}^{-1}$ mostly because of smaller attractive energy components making $\Delta E_{\text {int }}$ less favourable. This is mainly related to the longer $\mathrm{B}-\mathrm{O}$ bond in $[12-\mathrm{HCHO}]^{+}$compared to that in $[8-\mathrm{HCHO}]^{+}$, by $0.038 \AA$ A. The $\mathrm{B}-\mathrm{N}$ distances in the corresponding $\mathrm{NH}_{3}$-complexes vary by less than $0.01 \AA$ resulting in quite similar attractive interaction energy components, but larger Pauli repulsion in $\left[\mathbf{1 2}-\mathrm{NH}_{3}\right]^{+}$ (Table 1).

Sulfur substitution in 12 with oxygen to give $13(\mathrm{P}, \mathrm{O})$ decreases all interaction energy components and net $\Delta E_{\text {int }}$, but also $\Delta E_{\text {def }}$. The resulting HCHO affinity drops slightly by $\Delta H / \Delta E$ $=0.5 / 0.8 \mathrm{kcal} \mathrm{mol}^{-1}$. A change in $\Delta E_{\text {int }}$ partially comes from the change in the type of atoms, as already discussed, and partially from the increase in the $\mathrm{B}-\mathrm{OCH}_{2}$ distance by $0.025 \AA$. When two oxygen atoms are connected to boron, such as in $\mathbf{1 5}$, formaldehyde approach is even more impeded leading to the long boron-ligand distance of $1.682 \AA$ (by $0.056 \AA$ longer than in $[13-\mathrm{HCHO}]^{+}$and by $0.081 \AA$ longer than in $\left.[12-\mathrm{HCHO}]^{+}\right)$. This further decreases all interaction energy components. As decrease in attractive part is larger than decrease in the repulsive part, overall interaction energy becomes less favourable, which is the cause for the drop in HCHO affinities along the series: $12>13>15\left(\Delta E_{\text {def }}\right.$ decreases, as well $)$. This contrasts with the behaviour of $\mathrm{NH}_{3}$-complexes in which the $\mathrm{B}-\mathrm{N}$ distance in $\left[15-\mathrm{NH}_{3}\right]^{+}$is comparable to that in $\left[13-\mathrm{NH}_{3}\right]^{+}$and attractive interactions are just slightly reduced due to $\mathrm{P} \rightarrow \mathrm{O}$ exchange. In that case, the overall $\Delta E_{\text {int }}$ is increased in $\left[\mathbf{1 5}-\mathrm{NH}_{3}\right]^{+}$, compared to $\left[13-\mathrm{NH}_{3}\right]^{+}$(Table 1) because of the weaker Pauli repulsion associated with the $\mathrm{P} \rightarrow \mathrm{O}$ substitution. Since the calculated boron's p-orbital availability to accept electron density decreases in the order 13 (P,O; p-orbital occupancy 0.378e) > 15 (O,O; p-orbital occupancy 0.411e) $>12$ (P,S; p-orbital occupancy $0.542 \mathrm{e}$ ), it appears that the $\mathrm{B}-\mathrm{OCH}_{2}$ distance in the three HCHO-complexes is mainly affected by steric effects and it increases with increasing number of oxygen atoms: $1.601 \AA$ in 12 (P,S), 1.626 in 13 (P,O) and $1.682 \AA$ in 15 (O,O). The larger steric effect coming from oxygen atom should be ascribed to the short $\mathrm{B}-\mathrm{O}_{\text {ring }}$ bond lengths, making the $\mathrm{HCHO}$ approach more difficult. These effects are not pronounced in the case of more nucleophilic $\mathrm{NH}_{3}$.

In HCHO-adduct obtained from $16(\mathrm{~S}, \mathrm{O})$, the $\mathrm{B}-\mathrm{OCH}_{2}$ distance is marginally increased relative to that obtained from $13(\mathrm{P}, \mathrm{O})$ and its lower HCHO affinity by $\Delta H / \Delta E=2.9 / 3 \mathrm{kcal}$ $\mathrm{mol}^{-1}$ mainly stems from the large $\Delta E_{\mathrm{def}}=24.1 \mathrm{kcal} \mathrm{mol}^{-1}$, which is the largest value among all studied HCHO-adducts $\left(\Delta E_{\text {int }}\right.$ decreases by only $\left.0.8 \mathrm{kcal} \mathrm{mol}^{-1}\right)$. While all 13-16 have very similar affinities toward $\mathrm{NH}_{3}$ (Table 1), 14 (S,S) shows the weakest affinity for HCHO. This is the result of high $\Delta E_{\mathrm{def}}=$ $24 \mathrm{kcal} \mathrm{mol}^{-1}$ and high Pauli repulsion, whereas two sulfur atoms provide favourable electrostatic, orbital and dispersion interactions.

The remaining three cations 17-19, possessing one $\mathrm{N}_{\text {ring }}$ atom, form complexes with the longest $\mathrm{B}-\mathrm{OCH}_{2}$ distances (1.704-1.754 $\AA$ ). Cation 20 forms only hydrogen-bonded complex with HCHO. The long B-ligand bond should be ascribed to a combination of electronic (increase of boron's 
p-orbital occupancy) and steric effects, both more pronounced in complexes with the less nucleophilic formaldehyde. Although $[18-\mathrm{HCHO}]^{+}$features the longest $\mathrm{B}$-ligand distance amongst the 17-19, binding affinity of $18(\mathrm{~N}, \mathrm{O})$ is slightly greater than that of $\mathbf{1 9}(\mathrm{P}, \mathrm{N})$ and $\mathbf{1 7}(\mathrm{N}, \mathrm{S})$, of the latter two being almost the same. This trend is determined by $\Delta E_{\text {def }}$, which increase in the order: $\mathbf{1 8}<\mathbf{1 9}<\mathbf{1 7}$, while $\Delta E_{\text {int }}$ become more stabilizing in the same order. The changes in both energies are consistent with the decrease in the $\mathrm{B}-\mathrm{OCH}_{2}$ distances along the series $18>19>17$. These three cations show the smallest interaction energy upon complex formation, which concurs with results for $\mathrm{NH}_{3}$-adducts, and is partly affected by long boron-ligand distances. For example, in the case of $18(\mathrm{O}, \mathrm{N})$ steric hindrance to $\mathrm{HCHO}$ approach due to the short $\mathrm{B}-\mathrm{O}_{\text {ringl }}$ $\mathrm{N}_{\text {ring }}$ bonds $(1.340 / 1.376 \AA)$ combined with high boron's p-orbital occupancy $(0.457 \mathrm{e})$ keep formaldehyde relatively distant from boron atom. In fact, formation of hydrogenbonded adducts of 18 and 19 with HCHO is energetically more favoured (see section describing Geometries of borenium ion complexes).

Under solvent conditions, all binding energies are lowered by up to $11 \mathrm{kcal} \mathrm{mol}^{-1}$. The gas-phase obtained trend in $\Delta E \mathrm{~s}$ is retained, with small variations $(\mathbf{1 2}(\mathrm{P}, \mathrm{S})>\mathbf{1 1}(\mathrm{Cat}), \mathbf{1 4}(\mathrm{S}, \mathrm{S})$ and $16(\mathrm{O}, \mathrm{S})>15(\mathrm{O}, \mathrm{O})$ and $17(\mathrm{~N}, \mathrm{~S})>19(\mathrm{P}, \mathrm{N}))$.

\section{Chloride affinity of cations 4-20}

The chloride anion binding enthalpies $(\Delta H)$, energies $(\Delta E)$, LMOEDA results and boron-chlorine bond lengths are listed in Table 3. Gas-phase results are analyzed first and solvent effects are included in the last paragraph of this section.

Since the formation of chloride-adducts involve oppositely charged species, all binding energies are significantly larger than the previous ones. Binding enthalpies/energies span a range from $\Delta H / \Delta E=-119.4 / 119 \mathrm{kcal} \mathrm{mol}^{-1}$ for the weakest acceptor $20(\mathrm{~N}, \mathrm{~N})$ to $\Delta H / \Delta E=-165.3 / 165.3 \mathrm{kcal} \mathrm{mol}^{-1}$ for the strongest acceptor $5(\mathrm{~F}, \mathrm{~F}) . \Delta H \mathrm{~s}$ and $\Delta E \mathrm{~s}$ are more similar in this case $\left(R^{2}=0.999\right)$ and do not differ by more than $1.7 \mathrm{kcal} \mathrm{mol}^{-1}$ (the majority of values differ by less than $1 \mathrm{kcal} \mathrm{mol}^{-1}$ ). Deformation energies are larger with respect to the corresponding values calculated for $\mathrm{NH}_{3}$ - and $\mathrm{HCHO}-$ complexes, which could be ascribed to larger nucleophilicity of $\mathrm{Cl}^{-}$. They range from $22.2 \mathrm{kcal} \mathrm{mol}^{-1}$ for $4(\mathrm{H}, \mathrm{H})$ to $50.2 \mathrm{kcal} \mathrm{mol}^{-1}$ for $\mathbf{1 7}(\mathrm{N}, \mathrm{S})$. In this case, these energies correspond solely to deformation of borenium ion upon its reaction with $\mathrm{Cl}^{-}$. Boron-chlorine bond lengths vary from $1.833 \AA$ in 6 - $\mathrm{Cl}$ to $1.913 \AA$ in 20 -Cl. The LMOEDA shows that the nature of chloride-borenium cation interactions is primarily electrostatic. Percentage contribution of $\Delta E_{\text {elstat }}$ to all attractive interactions amounts $54.7-59.5 \%$. Next come orbital interactions, contribution of which ranges from $33.2-38.5 \%$, and the smallest stabilization is provided by dispersion forces, $6.8-8.6 \%$. Contribution of the latter is also smaller than in $\mathrm{NH}_{3}$ - and HCHO-complexes, which is expected for charged species.

The order of $\mathrm{Cl}^{-}$affinities differ from the order of $\mathrm{NH}_{3}$ and $\mathrm{HCHO}$ affinities. This could be related to $\mathrm{Cl}^{-}$increased nucleophilicity and stronger attractive forces with a cation, while Pauli repulsive energies compare with those observed for $\mathrm{NH}_{3}$ adducts. Thus, cation 5 (F,F) binds chloride more strongly than cation $4(\mathrm{H}, \mathrm{H})\left(\right.$ by $\left.\Delta H=2.8 \mathrm{kcal} \mathrm{mol}^{-1}\right)$, which originates from somewhat altered balance between interaction and deformation energies: $\Delta E_{\text {int }}$ overcomes $\Delta E_{\text {def }}$ to the extent that the total binding energy in 5-Cl exceeds the value in 4-Cl. Next comes the affinity of cation $6(\mathrm{Cl}, \mathrm{Cl})$, which is quite similar to that of 4 . In the case of $\mathrm{NH}_{3}$ and $\mathrm{HCHO}$ as ligands, the binding enthalpies of 4 and 6 differ by $\sim 9.5 \mathrm{kcal} \mathrm{mol}^{-1}$. This can also be explained by

Table 3 Calculated $\mathrm{B}-\mathrm{Cl}$ distances $\left(\mathrm{d}_{\mathrm{BCl}}, \AA\right)$, $\mathrm{Cl}^{-}$affinities $\left(\Delta H\right.$ at $298.15 \mathrm{~K}$ and $\Delta E$, values in italic are in $\mathrm{CH}_{2} \mathrm{Cl}_{2}$ ) and energy decomposition of binding interactions. ${ }^{a, b, c, d, e}$ All energy values are in $\mathrm{kcal} \mathrm{mol}^{-1}$

\begin{tabular}{|c|c|c|c|c|c|c|c|c|c|}
\hline Ion & $\mathrm{d}_{\mathrm{BCl}}$ & $\Delta H$ & $\Delta E$ & $\Delta E_{\mathrm{def}}$ & $\Delta E_{\text {int }}$ & $\Delta E_{\text {elstat }}$ & $\Delta E_{\text {ex+rep }}$ & $\Delta E_{\mathrm{oi}}$ & $\Delta E_{\text {disp }}$ \\
\hline 5 & 1.850 & -165.27 & $-165.30,-52.10$ & 40.14 & -205.44 & $-210.12(58.2 \%)$ & 155.61 & $-125.47(34.8 \%)$ & $-25.46(7.0 \%)$ \\
\hline 4 & 1.875 & -162.42 & $-164.11,-52.39$ & 22.25 & -186.36 & $-186.59(57.6 \%)$ & 137.62 & $-114.85(35.4 \%)$ & $-22.54(7.0 \%)$ \\
\hline 8 & 1.862 & -144.43 & $-144.79,-42.03$ & 36.20 & -180.99 & $-198.96(55.0 \%)$ & 180.57 & $-136.65(37.8 \%)$ & $-25.95(7.2 \%)$ \\
\hline 7 & 1.906 & -143.33 & $-144.30,-37.97$ & 26.19 & -170.49 & $-187.46(58.3 \%)$ & 150.83 & $-108.56(33.8 \%)$ & $-25.30(7.9 \%)$ \\
\hline 11 & 1.852 & -139.83 & $-139.47,-36.27$ & 40.84 & -180.31 & $-^{e}$ & 203.99 & $-^{e}$ & -25.25 \\
\hline 10 & 1.892 & -136.17 & $-136.15,-38.78$ & 34.56 & -170.71 & $-188.85(55.1 \%)$ & 171.85 & $-124.18(36.3 \%)$ & $-29.53(8.6 \%)$ \\
\hline 14 & 1.857 & -135.98 & $-135.98,-33.66$ & 41.95 & -177.93 & $-207.11(54.7 \%)$ & 200.99 & $-145.75(38.5 \%)$ & $-26.06(6.8 \%)$ \\
\hline 13 & 1.890 & -134.60 & $-134.48,-30.99$ & 29.02 & -163.50 & $-200.73(57.0 \%)$ & 188.59 & $-126.13(35.8 \%)$ & $-25.23(7.2 \%)$ \\
\hline 16 & 1.877 & -134.39 & $-134.23,-31.38$ & 36.61 & -170.84 & $-201.92(56.6 \%)$ & 186.20 & $-129.77(36.3 \%)$ & $-25.35(7.1 \%)$ \\
\hline 15 & 1.894 & -131.89 & $-131.36,-27.74$ & 38.42 & -169.78 & $-194.81(58.3 \%)$ & 164.37 & $-114.83(34.4 \%)$ & $-24.51(7.3 \%)$ \\
\hline 17 & 1.869 & -126.79 & $-126.32,-21.90$ & 50.15 & -176.47 & $-203.68(56.4 \%)$ & 184.55 & $-131.82(36.5 \%)$ & $-25.52(7.1 \%)$ \\
\hline
\end{tabular}

${ }^{a}$ Calculated at the M06-2X/6-311++G(d,p)//M06-2X/6-311++G(d,p) level. ${ }^{b}$ Gas-phase association enthalpies $(\Delta H)$, energies $(\Delta E)$ and all interaction energy terms are corrected for the BSSE by using the counterpoise method. ${ }^{c}$ Labeling of all energy terms is the same as in Table $1 .{ }^{d}$ Values in parentheses are percentage contribution to all attractive interactions. ${ }^{e}$ These values were not available. 
the altered balance between $\Delta E_{\text {int }}$ and $\Delta E_{\text {def. }}$ In the adduct 6-Cl, $\Delta E_{\text {elstat }}$ and $\Delta E_{\mathrm{oi}}$ are very favourable, and are the strongest compared to all other chloride-adducts. Dispersion interactions in 6-Cl are exceeded only by those in $\mathbf{9 - C l}$ and $\mathbf{1 0 - C l}$, obviously due to the presence of polarizable $\pi$-electrons in the latter two. These strong attractive forces in $6-\mathrm{Cl}$ are also attenuated by the large Pauli repulsion and deformation energy, which are both higher than those in 4-Cl. In fact, the two chlorine substituents in 6 also provide the strongest $\Delta E_{\text {elstat }}$ and $\Delta E_{\mathrm{oi}}$ in $\left[6-\mathrm{NH}_{3}\right]^{+}$ compared to all other ammonia-complexes, and very strong electrostatic and orbital interactions in $[6-\mathrm{HCHO}]^{+}$, exceeded by only those in $[8-\mathrm{HCHO}]^{+}$. The existence of strong attractive interactions in the case of $\mathbf{6}$ is also evident in very short B- $\mathrm{L}^{\prime}$ bonds.

The chloride affinity of $8(\mathrm{P}, \mathrm{P})(\Delta H / \Delta E=-144.4 /-144.8$ kcal mol $\left.{ }^{-1}\right)$ is slightly stronger than that of 7 (Me,Me) $(\Delta H / \Delta E=$ $-143.3 /-144.3 \mathrm{kcal} \mathrm{mol}^{-1}$ ) which differs from the order of $\mathrm{NH}_{3}$ and $\mathrm{HCHO}$ affinities. This again comes from a somewhat altered balance between $\Delta E_{\text {int }}$ and $\Delta E_{\text {def }}$, because all interaction energy components, as well as $\Delta E_{\mathrm{def}}$, are larger in the case of $\mathbf{8}$ and this concurs with $\mathrm{NH}_{3}$ - and $\mathrm{HCHO}$-adducts. [CatBNH$]_{3}^{+} \mathbf{1 1}$ binds $\mathrm{Cl}^{-}$slightly stronger $(\Delta H / \Delta E=-139.8 /-139.5 \mathrm{kcal}$ $\left.\mathrm{mol}^{-1}\right)$ than $9(\mathrm{Me}, \mathrm{Ph})\left(\Delta H / \Delta E=-138.3 /-139.3 \mathrm{kcal} \mathrm{mol}^{-1}\right)$ and stronger than $10(\mathrm{Ph}, \mathrm{Ph})(\Delta H / \Delta E=-136.2 /-136.2 \mathrm{kcal}$ $\left.\mathrm{mol}^{-1}\right)$. Since $\Delta E_{\text {int }}$ in $\mathbf{9 - C l}$ and $10-\mathrm{Cl}$ is very similar to $\Delta E_{\text {int }}$ in 7-Cl, weaker $\mathrm{Cl}^{-}$affinity of $\mathbf{9}$ and $\mathbf{1 0}$ compared to 7 is associated with larger deformation energies. The reversed order of $\mathrm{Cl}^{-}$ affinities, 11 being stronger acceptor than 9 and 10, comes from the short $\mathrm{B}-\mathrm{Cl}$ bond in 11-Cl, which is by $\sim 0.05 \AA$ shorter than in 9-Cl and 10-Cl. This leads to favourable $\Delta E_{\text {int }}$, which now overcomes $\Delta E_{\text {def }}$ to the larger extent.

Among the heterocycle-containing borenium cations 8 and 12-20, the affinity of $8(\mathrm{P}, \mathrm{P})$ toward $\mathrm{Cl}^{-}$is the largest $(\Delta H / \Delta E=$ $\left.-144.4 /-144.8 \mathrm{kcal} \mathrm{mol}^{-1}\right)$, next coming that of $12(\mathrm{P}, \mathrm{S})(\Delta H / \Delta E$ $\left.=-137.4 /-137.5 \mathrm{kcal} \mathrm{mol}^{-1}\right)$. This concurs with $\mathrm{NH}_{3}$ and $\mathrm{HCHO}$ affinities. Chloride affinities then follow the trend: $14(\mathrm{~S}, \mathrm{~S})>13$ $(\mathrm{P}, \mathrm{O}) \approx 16(\mathrm{~S}, \mathrm{O})>15(\mathrm{O}, \mathrm{O})>17(\mathrm{~N}, \mathrm{~S}) \approx 19(\mathrm{~N}, \mathrm{P})>18(\mathrm{~N}, \mathrm{O})>20$ $(\mathrm{N}, \mathrm{N})$, which partly reflects chloride steric demand. Thus, in the case of 8 and 12-16, the affinity drops as the sum of the two B-R/ $\mathrm{R}^{\prime}$ bonds become smaller, though it is clear that $\Delta H \mathrm{~s} / \Delta E \mathrm{~s}$ are determined by the final B-Cl distances, which do not follow the same trend. In fact, the worst correlation between $\Delta H \mathrm{~s} / \Delta E \mathrm{~s}$ and B-L' distances was found for $\mathrm{Cl}^{-}$as a ligand, suggesting that $\mathrm{Cl}^{-}$ interactions with other atoms are least dependent on its proximity to boron. The regularity between $\mathrm{Cl}^{-}$affinity and the sum of the two $\mathrm{B}-\mathrm{R} / \mathrm{R}^{\prime}$ bonds does not hold for nitrogen-containing heterocyclic ions 17-20. Here, a decrease in interaction energy fully follows the trend in binding enthalpies/energies (not found for $\mathrm{NH}_{3}$ and HCHO ligands). This trend of decreasing $\Delta E_{\mathrm{int}}$ is mostly determined by the magnitudes of orbital interactions, the drop of which is the most prominent. However, this should not be attributed only to electron-donating properties of heteroatoms connected to boron, since boron's p-orbital electron occupancy does not follow the same trend: it is the highest for $17(\mathrm{~N}, \mathrm{~S})$ having the largest $\mathrm{Cl}^{-}$affinity and highest $\Delta E_{\mathrm{oi}}$ among the four cations, 17-20, and the shortest B-Cl bond in the adduct. Obviously, other charge transfer interactions, polarization and electrostatic stabilization play an important role in determining the magnitude of total binding interactions.

Inclusion of solvent drastically reduces binding energies, by 97.4-113.2 kcal mol${ }^{-1}$. In solvent conditions, affinities toward $\mathrm{Cl}^{-}$are still stronger than affinities toward $\mathrm{HCHO}$ for all cations, but very similar with $\mathrm{NH}_{3}$ affinities. The trend in $\Delta E$ values is somewhat changed, that is $6(\mathrm{Cl}, \mathrm{Cl})>4(\mathrm{H}, \mathrm{H})$ and $5(\mathrm{~F}, \mathrm{~F}), 9(\mathrm{Me}$, $\mathrm{Ph})$ and $10(\mathrm{Ph}, \mathrm{Ph})>7(\mathrm{Me}, \mathrm{Me})$ and $16(\mathrm{O}, \mathrm{S})>13(\mathrm{P}, \mathrm{O})$.

\section{Effect of ligand (L) on $\mathrm{NH}_{3}, \mathrm{HCHO}$ and $\mathrm{Cl}^{-}$affinities of cations 21-29}

Calculated binding enthalpies $(\Delta H)$, energies $(\Delta E)$ and LMOEDA analysis of binding interactions between borenium ions 21-29 and $\mathrm{NH}_{3}, \mathrm{HCHO}$ and $\mathrm{Cl}^{-}$are presented in Table 4, along with the calculated $\mathrm{B}-\mathrm{L}^{\prime}\left(\mathrm{L}^{\prime}=\mathrm{NH}_{3}, \mathrm{HCHO}, \mathrm{Cl}\right)$ distances. All structures 21-29 contain 1,3,2-oxazaborolidine ring, also present in 18, and differ in ligand $\mathrm{L}$ positioned at the third coordination place of boron. The following three subsections contain analysis of the gas-phase results. Solvent effects analysis is included in a separate subsection.

\section{Ammonia affinities of cations 21-29}

Ammonia affinities of cations 21-24 and 26-29 range from $\Delta H$ / $\Delta E=-21 /-23.8 \mathrm{kcal} \mathrm{mol}^{-1}$ for $21\left(\mathrm{~L}=\mathrm{Me}_{2} \mathrm{~S}\right)$ to $\Delta H / \Delta E=-4.2 /$ $-6.6 \mathrm{kcal} \mathrm{mol}^{-1}$ for $29(\mathrm{~L}=2,6$-lutidine). As mentioned before, interaction of $25\left(\mathrm{~L}=\mathrm{PH}_{3}\right)$ with $\mathrm{NH}_{3}$ results in $\mathrm{PH}_{3}$ substitution. Except for 29, $\Delta H \mathrm{~s}$ and $\Delta E \mathrm{~s}$ show the same trend, with $R^{2}=$ 0.997. Deformation energies range from $26.1 \mathrm{kcal} \mathrm{mol}^{-1}$ for the complex formation from 27 ( $\mathrm{L}=$ 1,3-dimethylimidazol-2ylidene) to $39.6 \mathrm{kcal} \mathrm{mol}^{-1}$ for the association of ammonia with $22\left(\mathrm{~L}=\mathrm{Me}_{2} \mathrm{O}\right)$. Apart from $\left[21-\mathrm{NH}_{3}\right]^{+}$and $\left[29-\mathrm{NH}_{3}\right]^{+}$, interaction energies show the same trend as $\Delta H \mathrm{~s} / \Delta E \mathrm{~s}\left(R^{2}=0.96\right.$ for the correlation between $\Delta E$ and $\Delta E_{\text {int }}$ in the case of $\mathrm{NH}_{3}$ complexes with 22-28). The $\Delta E_{\text {int }}$ are thus important for the relative $\mathrm{NH}_{3}$ affinity order. Deformation energies decrease in the same order, that is from $\left[22-\mathrm{NH}_{3}\right]^{+}$to $\left[\mathbf{2 8}-\mathrm{NH}_{3}\right]^{+}$(for the latter, $\Delta E_{\text {def }}$ just slightly exceeds that for the $\left.\left[27-\mathrm{NH}_{3}\right]^{+}\right)$. The B- $\mathrm{NH}_{3}$ bond lengths vary from $1.624 \AA$ in $\left[22-\mathrm{NH}_{3}\right]^{+}$to $1.715 \AA$ in $\left[28-\mathrm{NH}_{3}\right]^{+}$. As a comparison, the calculated $\mathrm{B}-\mathrm{NH}_{3}$ bond length in $\left[18-\mathrm{NH}_{3}\right]^{+}$amounts $1.653 \AA$.

The LMOEDA shows that the nature of the cation- $\mathrm{NH}_{3}$ interactions is not much dependent on the structure of L: major percentage contribution to all attractive forces still comes from $\Delta E_{\text {elstat }}\left(46.8 \%\right.$ in $\left[21-\mathrm{NH}_{3}\right]^{+}$to $47.8 \%$ in $\left.\left[26-\mathrm{NH}_{3}\right]^{+}\right)$, followed by that of $\Delta E_{\mathrm{oi}}\left(39.9 \%\right.$ in $\left[28-\mathrm{NH}_{3}\right]^{+}$to $43.2 \%$ in $\left.\left[21-\mathrm{NH}_{3}\right]^{+}\right)$, though dispersion interactions are now slightly more pronounced ranging from $10 \%$ in $\left[21-\mathrm{NH}_{3}\right]^{+}$to $12.4 \%$ in $\left[28-\mathrm{NH}_{3}\right]^{+}$.

Replacement of ammonia ligand $\mathrm{L}$ in $\mathbf{1 8}$ with weaker nucleophiles (better leaving groups) such as $\mathrm{Me}_{2} \mathrm{~S}$ in 21 and $\mathrm{Me}_{2} \mathrm{O}$ in 22 increases $\mathrm{NH}_{3}$ affinity by $2.3 \mathrm{kcal} \mathrm{mol}^{-1}$ and $1.6 \mathrm{kcal}$ $\mathrm{mol}^{-1}$, respectively. The $\mathrm{B}-\mathrm{NH}_{3}$ distance in a complex reduces by $\sim 0.028 \AA$. In fact, nitrogen from the incoming $\mathrm{NH}_{3}$ ligand forms stronger bond with boron than sulfur and oxygen from dimethyl(thio)ether, resulting in a significant increase in the B- $\mathrm{SMe}_{2}$ and $\mathrm{B}-\mathrm{OMe}_{2}$ bond lengths by $0.201 \AA$ and $0.214 \AA$, respectively. 
Table 4 Calculated $\mathrm{B}-\mathrm{L}^{\prime}$ distances $\left(d_{\mathrm{BL}}, \AA\right)$, $\mathrm{L}^{\prime}$ affinities $\left(\Delta H\right.$ at $298.15 \mathrm{~K}$ and $\Delta E$, values in italic are in $\mathrm{CH}_{2} \mathrm{Cl}_{2}$ ) and energy decomposition of binding interactions. ${ }^{a, b, c, d, e}$ All energy values are in $\mathrm{kcal} \mathrm{mol}^{-1}$

\begin{tabular}{|c|c|c|c|c|c|c|c|c|c|c|}
\hline Ion & $\mathrm{L}^{\prime}$ & $d_{\mathrm{BL}^{\prime}}$ & $\Delta H$ & $\Delta E$ & $\Delta E_{\text {def }}$ & $\Delta E_{\text {int }}$ & $\Delta E_{\text {elstat }}$ & $\Delta E_{\text {ex }+ \text { rep }}$ & $\Delta E_{\mathrm{oi}}$ & $\Delta E_{\text {disp }}$ \\
\hline 21 & $\mathrm{NH}_{3}$ & 1.626 & -20.99 & $-23.80,-25.74$ & 30.31 & -54.11 & $-113.20(46.8 \%)$ & 187.75 & $-104.55(43.2 \%)$ & $-24.11(10.0 \%)$ \\
\hline 22 & $\mathrm{NH}_{3}$ & 1.624 & -20.27 & $-22.43,-23.25$ & 39.58 & -62.01 & $-109.22(47.0 \%)$ & 170.17 & $-98.69(42.5 \%)$ & $-24.27(10.5 \%)$ \\
\hline 24 & $\mathrm{NH}_{3}$ & 1.651 & -13.35 & $-15.02,-17.04$ & 28.00 & -43.02 & $-107.17(47.3 \%)$ & 183.70 & $-96.05(42.4 \%)$ & $-23.50(10.3 \%)$ \\
\hline 26 & $\mathrm{NH}_{3}$ & 1.694 & -8.76 & $-10.76,-12.21$ & 27.89 & -38.65 & $-97.85(47.8 \%)$ & 166.21 & $-82.97(40.5 \%)$ & $-24.04(11.7 \%)$ \\
\hline 27 & $\mathrm{NH}_{3}$ & 1.711 & -6.26 & $-8.20,-9.55$ & 26.10 & -34.30 & $-93.43(47.7 \%)$ & 161.51 & $-78.25(40.0 \%)$ & $-24.13(12.3 \%)$ \\
\hline 24 & $\mathrm{HCHO}$ & 2.650 & -10.25 & $-11.51,-7.01$ & 0.89 & -12.40 & $-14.78(45.4 \%)$ & 21.31 & $-5.39(16.5 \%)$ & $-12.40(38.1 \%)$ \\
\hline 21 & $\mathrm{HCHO}$ & 1.668 & -9.16 & $-11.27,-8.64$ & 20.02 & -31.29 & $-76.78(45.1 \%)$ & 138.99 & $-70.18(41.2 \%)$ & $-23.32(13.7 \%)$ \\
\hline 25 & $\mathrm{HCHO}$ & 1.640 & -8.66 & $-10.18,-4.26$ & 23.96 & -34.14 & $-82.23(45.2 \%)$ & 147.81 & $-77.46(42.6 \%)$ & $-22.26(12.2 \%)$ \\
\hline 22 & $\mathrm{HCHO}$ & 1.669 & -8.36 & $-10.06,-6.49$ & 27.81 & -37.87 & $-74.46(45.3 \%)$ & 126.56 & $-66.03(40.2 \%)$ & $-23.94(14.5 \%)$ \\
\hline 26 & $\mathrm{HCHO}$ & 2.678 & -8.32 & $-9.88,-5.85$ & 0.50 & -10.38 & $-12.37(44.4 \%)$ & 17.47 & $-4.34(15.6 \%)$ & $-11.14(40.0 \%)$ \\
\hline 28 & $\mathrm{HCHO}$ & 2.700 & -8.25 & $-9.66,-5.96$ & 0.45 & -10.11 & $-11.87(42.5 \%)$ & 17.82 & $-3.91(14.0 \%)$ & $-12.15(43.5 \%)$ \\
\hline 24 & $\mathrm{Cl}^{-}$ & 1.913 & -111.32 & $-111.84,-17.29$ & 35.03 & -146.87 & $-188.77(56.8 \%)$ & 185.70 & $-117.12(35.2 \%)$ & $-26.68(8.0 \%)$ \\
\hline 26 & $\mathrm{Cl}^{-}$ & 1.939 & -100.69 & $-101.57,-11.41$ & 39.14 & -141.94 & $-^{e}$ & 172.34 & $-^{e}$ & -27.19 \\
\hline 29 & $\mathrm{Cl}^{-}$ & 1.925 & -99.71 & $-100.82,-8.72$ & 46.76 & -147.58 & $-182.01(56.5 \%)$ & 174.30 & $-111.72(34.7 \%)$ & $-28.15(8.8 \%)$ \\
\hline 28 & $\mathrm{Cl}^{-}$ & 1.968 & -99.22 & $-100.01,-10.75$ & 34.53 & -134.54 & $-172.88(57.2 \%)$ & 167.75 & $-102.25(33.8 \%)$ & $-27.16(9.0 \%)$ \\
\hline 27 & $\mathrm{Cl}^{-}$ & 1.976 & -99.20 & $-99.44,-8.67$ & 33.75 & -133.19 & $-172.52(58.0 \%)$ & 164.09 & $-98.33(33.1 \%)$ & $-26.43(8.9 \%)$ \\
\hline
\end{tabular}

${ }^{a}$ Calculated at the M06-2X/6-311++G(d,p)//M06-2X/6-311++G(d,p) level. ${ }^{b}$ Gas-phase association enthalpies $(\Delta H)$, energies $(\Delta E)$ and all interaction energy terms are corrected for the BSSE by using the counterpoise method. ${ }^{c}$ Labeling of all energy terms is the same as in Table $1 .{ }^{d}$ Values in parentheses are percentage contribution to all attractive interactions. ${ }^{e}$ These values were not available.

The corresponding B-L bond lengthening upon complex formation with $18\left(\mathrm{~L}=\mathrm{NH}_{3}\right), 23\left(\mathrm{~L}=\mathrm{NMe}_{3}\right)$ and $24\left(\mathrm{~L}=\mathrm{PMe}_{3}\right)$ is smaller: $0.104 \AA$ for the $\mathrm{B}-\mathrm{NH}_{3}, 0.103 \AA$ for the $\mathrm{B}-\mathrm{NMe}_{3}$ and $0.083 \AA$ for the $\mathrm{B}-\mathrm{PMe}_{3}$ bond. The shorter $\mathrm{B}-\mathrm{N}$ bond in [21$\left.\mathrm{NH}_{3}\right]^{+}$and $\left[22-\mathrm{NH}_{3}\right]^{+}$relative to $\left[18-\mathrm{NH}_{3}\right]^{+}$and adducts obtained from 23, 24 and 26-29, leads to quite favourable interaction energy. It is more stabilizing in $\left[22-\mathrm{NH}_{3}\right]^{+}$than in $\left[21-\mathrm{NH}_{3}\right]^{+}$just because of the smaller Pauli repulsion. These favourable $\Delta E_{\text {int }}$ are attenuated by $\Delta E_{\mathrm{def}}$, which is larger for $\mathbf{2 2}$.

The presence of $\mathrm{L}=\mathrm{NMe}_{3}$ in 23 and $\mathrm{L}=\mathrm{PMe}_{3}$ in 24 decrease complex formation enthalpies by $4.2 \mathrm{kcal} \mathrm{mol}^{-1}$ and $5.4 \mathrm{kcal}$ $\mathrm{mol}^{-1}$, respectively, compared to 18. Since $\Delta E_{\mathrm{def}}$ are smaller than in the case of 18, weaker $\mathrm{NH}_{3}$ affinity of 23 and 24 is associated with a decrease in the $\Delta E_{\text {int }}$. Thus, substitution of $\mathrm{L}$ $=\mathrm{NH}_{3}$ in 18 with the larger ligand $\mathrm{NMe}_{3}$ increases the $\mathrm{B}-\mathrm{NH}_{3}$ distance by $0.016 \AA$. This, in turn, weakens orbital and electrostatic stabilization by $4.6 \mathrm{kcal} \mathrm{mol}^{-1}$ and $2 \mathrm{kcal} \mathrm{mol}^{-1}$, respectively. Otherwise, charge transfer interactions corresponding to the $\mathrm{B}-\mathrm{NH}_{3}$ bond formation should be increased due to the somewhat lower boron's p-orbital occupancy in 23 $(0.438 \mathrm{e})$ than in $18(0.457 \mathrm{e})$. The $\mathrm{NMe}_{3}$ stabilizing ligand brings about larger Pauli repulsion in the complex, though larger by only $2.8 \mathrm{kcal} \mathrm{\textrm {mol } ^ { - 1 }}$ with respect to that in $\left[\mathbf{1 8}-\mathrm{NH}_{3}\right]^{+}$. The complex geometry is obviously adjusted to escape strong repulsive interactions, for example by somewhat increased cation-ligand distance. As data in Table 4 show, even in this case the dispersion interactions are larger in $\left[23-\mathrm{NH}_{3}\right]^{+}$than in $\left[18-\mathrm{NH}_{3}\right]^{+}$. The presence of phosphorus in 24 instead of nitrogen in 23 leads to the shorter $\mathrm{B}-\mathrm{NH}_{3}$ bond, quite similar to that in $\left[18-\mathrm{NH}_{3}\right]^{+}$, and larger electrostatic and orbital stabilization. The ammonia approach is here less hindered due to the longer B- $\mathrm{PMe}_{3}$ bond (1.939 $\mathrm{A}$ ) with respect to B-NMe 3 bond (1.535 $\left.\mathrm{A}\right)$. What makes 24 to be weaker $\mathrm{NH}_{3}$ acceptor than both 18 and 23 is complex destabilization by larger Pauli repulsion.

All carbene-stabilized cations 26-28 form more labile adducts with ammonia than all the previously discussed ones. The $\Delta H \mathrm{~s} /$ $\Delta E$ s decrease in the order: $26\left(\Delta H / \Delta E=-8.8 /-10.8 \mathrm{kcal} \mathrm{mol}^{-1}\right)>$ $27\left(\Delta H / \Delta E=-6.3 /-8.2 \mathrm{kcal} \mathrm{mol}^{-1}\right)>28(\Delta H / \Delta E=-4.8 /-6.3$ kcal $\left.\mathrm{mol}^{-1}\right)$. These cations keep ammonia at relatively long distance, 1.694-1.715 ̊, resulting in smaller Pauli repulsion, but also in weaker attractive energies $\left(\Delta E_{\text {elstat }}\right.$ and $\left.\Delta E_{\mathrm{oi}}\right)$. Calculated boron's p-orbital occupancy amounts $0.441 \mathrm{e}$ in $26,0.436 \mathrm{e}$ in 27 and $0.430 \mathrm{e}$ in 28, which are all smaller than in 18 (0.457e) and majority of cations 21-24 (Table S3 $\dagger$ ). This means that the lower $\mathrm{NH}_{3}$ affinities of 26-28 do not originate from smaller capability of boron's p-orbital to accept an electron pair. Rather, it seems as if steric factors interfere with ligand approach, keeping it somewhat farther from boron and thus decreasing the cation- $\mathrm{L}^{\prime}$ interaction energy. This is the cause of smaller binding energy of these cations, since $\Delta E_{\text {def }}$ is also smaller than in the case of $\mathbf{1 8}$ and 21-24. Among the three carbene-stabilized cations, $26(\mathrm{~L}=$ 3-methylthiazole-2-ylidene) shows the highest affinity and $28(\mathrm{~L}=$ 1,3-dimethybenzimidazole-2-ylidene) is the weakest $\mathrm{NH}_{3}$ acceptor. Higher affinity of $\mathbf{2 6}$ comes from more favourable $\Delta E_{\text {int }}$, related to the smaller steric hindrance to ligand approach and shorter B-N bond. Only in $\left[\mathbf{2 6}-\mathrm{NH}_{3}\right]^{+}$the 1,3,2-oxazaborolidine 
and thiazole rings are quasiorthogonal, with $\mathrm{NH}_{3}$ situated at the sulfur side of thiazole. In the other two adducts, the two rings adopt a wing-shaped conformation. The $\mathrm{B}-\mathrm{N}$ bond lengths in $\left[27-\mathrm{NH}_{3}\right]^{+}$and $\left[28-\mathrm{NH}_{3}\right]^{+}$are almost the same, and the lower affinity of 28 mainly comes from a decrease in $\Delta E_{\text {int }}$ (by $1.6 \mathrm{kcal}$ $\mathrm{mol}^{-1}$ relative to $\left[27-\mathrm{NH}_{3}\right]^{+}$), less from increase in $\Delta E_{\text {def }}$, by only $0.3 \mathrm{kcal} \mathrm{mol}^{-1}$. The amount of electrostatic, orbital and dispersion interactions in $\left[28-\mathrm{NH}_{3}\right]^{+}$compares with those in $\left[27-\mathrm{NH}_{3}\right]^{+}$, so the smaller $\Delta E_{\text {int }}$ of $\left[\mathbf{2 8}-\mathrm{NH}_{3}\right]^{+}$originates from an increased Pauli repulsion.

The weaker $\mathrm{NH}_{3}$ affinity of 29 relative to affinities of 26-28 stems from an increased deformation energy needed to accommodate $\mathrm{NH}_{3}$. The most favourable geometry of cation $\mathbf{2 9}$, having the two rings in an orthogonal position, must change to a wing-shaped one to allow $\mathrm{NH}_{3}$ to approach boron atom. When the complex is formed, the interaction energy becomes more stabilizing than in adducts formed from 26-28.

\section{Formaldehyde affinities of cations 21-29}

Formaldehyde affinities of cations 21-28 span a narrow range from $\Delta H / \Delta E=-10.2 /-11.5 \mathrm{kcal} \mathrm{mol}^{-1}$ for $24\left(\mathrm{~L}=\mathrm{PMe}_{3}\right)$ to $\Delta H /$ $\Delta E=-6.5 /-8.2 \mathrm{kcal} \mathrm{mol}^{-1}$ for $23\left(\mathrm{~L}=\mathrm{NMe}_{3}\right)$, and are all smaller than the affinity of $18\left(\mathrm{~L}=\mathrm{NH}_{3}\right)$. As mentioned before, 29 ( $\mathrm{L}=$ lut) forms only hydrogen-bonded complex with HCHO. The trend in $\Delta H \mathrm{~s}$ and $\Delta E \mathrm{~s}$ is the same, having $R^{2}=0.929$. Interaction and deformation energies vary greatly (Table 4 ) due to large variations in the $\mathrm{B}-\mathrm{OCH}_{2}$ distances. They are pretty long (2.650-2.778 $\AA$ ) in HCHO-complexes with cations $24\left(\mathrm{~L}=\mathrm{PMe}_{3}\right)$ and 26-28 (carbene-stabilized) resulting in small deformation (0.4-0.9 $\left.\mathrm{kcal} \mathrm{mol}^{-1}\right)$ and small interaction energies $(-9.2$ to $\left.-12.4 \mathrm{kcal} \mathrm{mol}^{-1}\right)$. In other $\mathrm{HCHO}$-adducts, boron-ligand distances are shorter and range from $1.640 \AA$ in $\left[25-\mathrm{HCHO}^{+}\right.$ $\left(\mathrm{L}=\mathrm{PH}_{3}\right)$ to $1.824 \AA$ in $[23-\mathrm{HCHO}]^{+}\left(\mathrm{L}=\mathrm{NMe}_{3}\right)$.

The LMOEDA shows that in all adducts having long boronligand distances the percentage contributions of electrostatic and dispersion forces $(42.5-46.7 \%$ and $38.1-43.5 \%$, respectively) to all attractive interactions is much greater than the contribution of orbital interactions (3.3-16.5\%). Therefore, they should be considered as electrostatic-dispersion adducts rather than coordinate covalent ones. In other complexes, the percentage contributions of the three attractive interactions are more similar to those found for adducts derived from 4-20.

It is not clear why $\mathbf{2 4}$ forms an adduct with such a long B- $\mathrm{OCH}_{2}$. Steric factors may be involved, and they are more prominent in the case of the less nucleophilic $\mathrm{HCHO}$ than for $\mathrm{NH}_{3}$ and $\mathrm{Cl}^{-}$. Nevertheless, the weak $\Delta E_{\text {int }}$ in $[24-\mathrm{HCHO}]^{+}$is counteracted by the very small energy required to deform fragments at such large distances, and is strong enough to place $\mathbf{2 4}$ at the beginning of the affinity scale of 21-28. By contrast, its nitrogen counterpart $\mathbf{2 3}$ binds $\mathrm{HCHO}$ at shorter distance increasing both $\Delta E_{\text {int }}$ and $\Delta E_{\text {def }}$, though they are still smaller than in the case of 18, due to longer $\mathrm{B}-\mathrm{OCH}_{2}$ distance. The latter could be induced by steric repulsion with $\mathrm{NMe}_{3}$ in 23. The relative magnitudes of $\Delta E_{\text {int }}$ and $\Delta E_{\text {def }}$ determined the lowest HCHO affinity of 23 amongst 18, 21, 22 and 24-28. Due to longer B-ligand distance, the role of dispersion attraction in complex stabilization is increased in $[23-\mathrm{HCHO}]^{+}$, at the expense of $\Delta E_{\mathrm{oi}}$, compared to adducts derived from 4-20 and 21, 22, 24 and 25.

Cations 21, 22 and 25, containing better leaving groups $\mathrm{L}=$ $\mathrm{SMe}_{2}, \mathrm{OMe}_{2}$ and $\mathrm{PH}_{3}$, respectively, form complexes with short B- $\mathrm{OCH}_{2}$ bonds which inherently increases interaction and deformation energies, compared to those corresponding for the complex formation from 18, 23 and 24 . The 21, 22 and 25 are weaker $\mathrm{HCHO}$ acceptors than 18 and 24 just because of larger deformations, but stronger acceptors than $\mathbf{2 3}$ due to the increased interaction energy. The trend of decreasing HCHO affinities along the series $\mathbf{2 1}>\mathbf{2 5}>\mathbf{2 2}$ is determined by their $\Delta E_{\text {def }}$ which increase in the same order, while $\Delta E_{\text {int }}$ become more stabilizing. As in the case of $\mathrm{NH}_{3}$-complexes, the B-ligand distances in $\left[21-\mathrm{HCHO}^{+}\right.$and $\left[22-\mathrm{HCHO}^{+}\right.$are almost the same and the more favourable $\Delta E_{\text {int }}$ for the latter results from smaller Pauli repulsion, whereas sulfur in $\mathbf{2 1}$ provides more electrostatic and orbital stabilization. The latter possibly comes from polarization part, since boron's p-orbital occupancy in 21 $(0.474 \mathrm{e})$ is higher than in $22(0.447 \mathrm{e})$.

The three carbene-stabilized cations 26-28 show quite similar affinities toward formaldehyde, which also compare with that of 22. The highest and the lowest enthalpy differ by only $0.6 \mathrm{kcal} \mathrm{mol}^{-1}$, while ammonia affinities of cations 26 and 28 differ by $\sim 4 \mathrm{kcal} \mathrm{mol}^{-1}$, which should be related to $\mathrm{NH}_{3}$ closer approach to boron thus more influencing interaction and deformation energy parts. In fact, 27 and 28 show smaller tendency to bind ammonia than to bind formaldehyde, while $\mathrm{NH}_{3}$ and $\mathrm{HCHO}$ affinities of $\mathbf{2 6}$ are comparable.

\section{Chloride affinities of cations 21-29}

The enthalpies/energies for the formation of adducts between cations 22-24, 26-29 and chloride anion are all lower than $\Delta H$ / $\Delta E$ for the corresponding $\mathrm{Cl}^{-}$association with 18. They range from $\Delta H / \Delta E=-119.8 /-120.6 \mathrm{kcal} \mathrm{mol}^{-1}$ for $22\left(\mathrm{~L}=\mathrm{OMe}_{2}\right)$ to $\Delta H / \Delta E=-99.2 /-99.4 \mathrm{kcal} \mathrm{mol}^{-1}$ for $27(\mathrm{~L}=1,3-$ dimethylimidazole-2-ylidene). As already mentioned, $\mathrm{Cl}^{-}$ substitutes ligand $\mathrm{L}$ in cations $21\left(\mathrm{~L}=\mathrm{SMe}_{2}\right)$ and $25\left(\mathrm{~L}=\mathrm{PH}_{3}\right)$. $\Delta H \mathrm{~s}$ and $\Delta E \mathrm{~s}$ are strongly correlated $\left(R^{2}=0.999\right)$. With just one exception (cation 29), interaction energies follow the same trend as $\Delta H \mathrm{~s} / \Delta E \mathrm{~s}$ and are thus important for the relative $\mathrm{Cl}^{-}$ affinity order. Deformation energies, reflecting solely geometry changes of borenium ions, vary from $33.8 \mathrm{kcal} \mathrm{mol}^{-1}$ for association of $\mathrm{Cl}^{-}$with 27 ( $\mathrm{L}=1,3$-dimethylimidazol-2-ylidene) to $57.3 \mathrm{kcal} \mathrm{mol}^{-1}$ for the adduct formation between $\mathrm{Cl}^{-}$and 22 $\left(\mathrm{L}=\mathrm{OMe}_{2}\right)$. The $\mathrm{B}-\mathrm{Cl}$ bond lengths range from $1.849 \AA$ in $22-\mathrm{Cl}$ to $1.976 \AA$ in $27-\mathrm{Cl}$. The $\mathrm{B}-\mathrm{Cl}$ bond length in $18-\mathrm{Cl}$ is intermediate and amounts $1.905 \AA$.

The LMOEDA results show that the nature of the cationchloride interactions in adducts derived from 22-24 and 26-29 is the same as in adducts formed from 4-20: the main percentage contribution to all attractive interactions comes from $\Delta E_{\text {elstat }}(55-58 \%)$, next come orbital interactions (33.1$37.4 \%$ ), and dispersion forces provide the smallest contribution $(7.6-9 \%)$. 
As in the case of $\mathrm{L}^{\prime}=\mathrm{NH}_{3}$ and $\mathrm{HCHO}$, substitution of $\mathrm{L}=$ $\mathrm{NH}_{3}$ in 18 for better leaving group $\mathrm{OMe}_{2}$ in 22, decreases the B- $\mathrm{L}^{\prime}$ distance. In the case of $\mathrm{Cl}^{-}$, the exocyclic $\mathrm{B}-\mathrm{O}$ bond in 22 is significantly elongated upon adduct formation, by $0.294 \AA$, while the newly formed B-Cl bond is by $0.086 \AA$ longer than it would be if a full $\mathrm{OMe}_{2}$ substitution occurred. Large geometry changes in the cation leading to high $\Delta E_{\text {def }}$ are responsible for weaker $\mathrm{Cl}^{-}$affinity of 22 compared to 18, even though interaction energy increases by as much as $12.5 \mathrm{kcal} \mathrm{mol}^{-1}$. When better nucleophiles than $\mathrm{NH}_{3}$ are bound to boron, such as $\mathrm{NMe}_{3}$ and $\mathrm{PMe}_{3}$ in cations 23 and $\mathbf{2 4}$, respectively, the $\mathrm{Cl}^{-}$affinity drops by more than $10 \mathrm{kcal} \mathrm{mol}^{-1}$. The presence of $\mathrm{NMe}_{3}$ in 23 instead of $\mathrm{NH}_{3}$ in 18 results in just a slight $\mathrm{B}-\mathrm{Cl}$ bond elongation $(<0.01 \AA)$, which is smaller than in the case of $\mathrm{L}^{\prime}=\mathrm{NH}_{3}$ and $\mathrm{HCHO}$ and can be attributed to the larger nucleophilicity of $\mathrm{Cl}^{-}$. The reason why 23 behaves as weaker $\mathrm{Cl}^{-}$acceptor than 18 lies in the smaller interaction energy, made such mostly by increase/decrease in the Pauli/electrostatic interactions, while orbital and dispersion interactions are more favourable in the case of 23 . The $\mathrm{B}-\mathrm{Cl}$ bond in $\mathbf{2 4}-\mathrm{Cl}$ is the same as in $\mathbf{2 3}-\mathrm{Cl}$ and smaller $\mathrm{Cl}^{-}$affinity of $\mathbf{2 4}$ relates to larger repulsive energy (by $8.2 \mathrm{kcal} \mathrm{mol}^{-1}$ ), but curiously to a drop in $\Delta E_{\text {elstat }}$ by $\sim 3 \mathrm{kcal}$ $\mathrm{mol}^{-1}$ and $\Delta E_{\text {disp }}$ by $1.9 \mathrm{kcal} \mathrm{mol}^{-1}$. This could be explained by the longer distances between $\mathrm{Cl}$ and atoms contained in the ligand $\mathrm{L}$, due to longer $\mathrm{B}-\mathrm{P}$ bond relative to $\mathrm{B}-\mathrm{N}$ bond. The reason why 23 and 24 are weaker $\mathrm{Cl}^{-}$acceptors than 22 is a drop in $\Delta E_{\text {int }}$, related to longer $\mathrm{B}-\mathrm{Cl}$ bonds, which outweighs the drop in $\Delta E_{\text {def }}$.

The $\mathrm{Cl}^{-}$affinities of carbene-stabilized cations 26-28 and lutstabilized cation 29 are all within $1.5 \mathrm{kcal} \mathrm{mol}^{-1}$, the highest affinity found for 26 ( $\mathrm{L}=3$-methylthiazole-2-ylidene) and the lowest for 27 ( $\mathrm{L}=1$ 1,3-dimethylimidazole-2-ylidene). Cation 26 binds $\mathrm{Cl}^{-}$at shorter distance than the related cations 27 and 28, resulting in significantly higher interaction energy, but also more energy costly geometry changes (near-to-planar geometry in 26 becomes orthogonal in the adduct, with $\mathrm{Cl}$ being positioned at the sulfur side of thiazole ring). Their relative magnitudes are such that $\mathbf{2 6}$ shows slightly higher affinity toward $\mathrm{Cl}^{-}$than 27 and 28, whose affinities are the same. Although, 29-Cl formation results in a (significantly) more favourable interaction energy than the adduct formation from the carbene-stablized ions 26-28, the high deformation energy places the $\mathrm{Cl}^{-}$affinity of 29 close to those of 26-28. In this case, too, high $\Delta E_{\text {def }}$ mostly originates from cation geometry change from orthogonal to the wing-shaped, which is necessary in order to make a space for the incoming ligand.

Generally, borenium cations 21-25 having $\mathrm{L}$ with $\mathrm{sp}^{3}$ hybridized heteroatom possess higher affinities toward a new ligand $\mathrm{L}^{\prime}$ than carbene-stabilized cations 26-28 and lutstabilized cation 29 . In the case of 29 , its weak affinity is determined by high $\Delta E_{\text {def }}$ and smaller $\Delta E_{\text {int }}$, the latter partly related to the longer $\mathrm{B}-\mathrm{L}^{\prime}$ distance compared to that in adducts derived from 21-25. The smaller binding energies of 26-28 have to be attributed to lower interaction energies, which is primarily due to the long $\mathrm{B}-\mathrm{L}^{\prime}$ distances, particularly in the case of $\mathrm{HCHO}-$ adducts. The relative order of $\mathrm{L}^{\prime}$ affinities compares when $\mathrm{L}^{\prime}=$ $\mathrm{NH}_{3}$ and $\mathrm{Cl}^{-}$, but differs significantly when $\mathrm{L}^{\prime}=\mathrm{HCHO}$.

\section{Solvent effects on $\mathbf{L}^{\prime}$ affinity of cations 21-29}

Solvent affects binding energies in the same way as discussed before: chloride affinities are significantly reduced and are still larger than $\mathrm{HCHO}$ affinities, which are decreased by up to $6 \mathrm{kcal}$ $\mathrm{mol}^{-1}$. Affinities toward $\mathrm{Cl}^{-}$and $\mathrm{NH}_{3}$ become similar. The trend in $\Delta E$ s when $\mathrm{L}^{\prime}=\mathrm{NH}_{3}$ is the same as in the gas-phase, almost the same when $\mathrm{L}^{\prime}=\mathrm{Cl}^{-}$(one exception: $28>29$ ) and somewhat changed when $\mathrm{L}^{\prime}=\operatorname{HCHO}\left(21\left(\mathrm{~L}=\mathrm{SMe}_{2}\right)>24\left(\mathrm{~L}=\mathrm{PMe}_{3}\right), 25\left(\mathrm{PH}_{3}\right)\right.$ $<27\left(\mathrm{~L}=1\right.$,3-dimethylimidazol-2-ylidene) and $\left.23\left(\mathrm{NMe}_{3}\right)>27\right)$.

\section{Conclusions}

In this paper, we have theoretically studied borenium ion affinities toward the three ligands: $\mathrm{L}^{\prime}=\mathrm{NH}_{3}, \mathrm{HCHO}$ and $\mathrm{Cl}^{-}$. General trend in both gas- and liquid-phase is such that $\mathrm{R} / \mathrm{R}^{\prime}=$ $\mathrm{H}, \mathrm{F}, \mathrm{Cl}$ provide the strongest $\mathrm{L}^{\prime}$ binding. Then come cations with $\mathrm{R} / \mathrm{R}^{\prime}=\mathrm{Me}$ and $\mathrm{P}$, the latter contained in the five-membered heterocycle. Substitution of Me groups with one or two $\mathrm{Ph}$ decreases affinity toward the $\mathrm{L}^{\prime}$ (in solvent conditions the influence on $\mathrm{Cl}^{-}$affinity is opposite). Cat-containing cation shows higher affinity than other studied heterocycle-containing cations, in which $\mathrm{R} / \mathrm{R}^{\prime}=\mathrm{O}, \mathrm{S}, \mathrm{N}$ and $\mathrm{P}$, except the cation $8(\mathrm{P}, \mathrm{P})$ in the gas-phase, and 8 and $12(\mathrm{P}, \mathrm{S})$ in the solvent, when $\mathrm{L}^{\prime}=$ $\mathrm{NH}_{3}$ and HCHO. The high calculated affinity of 8 has been attributed to the long B-P bonds, which sterically least impedes with ligand approach. Among the heterocyclic cations, those that possess $\mathrm{O}, \mathrm{S}$ and $\mathrm{P}$ as heteroatoms show stronger tendency to bind new ligand than nitrogen-containing ones. The variations of L showed that, with two exceptions, $\mathrm{Me}_{2} \mathrm{~S}-, \mathrm{Me}_{2} \mathrm{O}-, \mathrm{H}_{3} \mathrm{~N}-$, $\mathrm{Me}_{3} \mathrm{~N}$ - and $\mathrm{Me}_{3} \mathrm{P}$-stabilized borenium cations bind $\mathrm{L}^{\prime}$ more strongly than carbene- and 2,6-lutidine-stabilized cations.

When $\mathrm{L}=$ constant, the observed trend is determined by the cation-ligand distances and type of substituents $R / R^{\prime}$. It was found that heteroatoms from the second octal row of the periodic table $(\mathrm{P}, \mathrm{S}, \mathrm{Cl})$ provide larger electrostatic and orbital stabilization than heteroatoms from the first row $(\mathrm{N}, \mathrm{O}, \mathrm{F})$ and it appears that the stabilizing effect increases when going from left to the right in the period. However, the repulsive Pauli energy is also stronger for larger heteroatoms. Phenyl substituents show larger electrostatic, orbital and dispersion stabilization than methyl groups, but also larger repulsion. It is the relative magnitude of attractive and repulsive interactions, along with the $\mathrm{B}-\mathrm{L}^{\prime}$ distance that determines the overall interaction energy. When $\mathrm{L}^{\prime}=\mathrm{NH}_{3}$ and HCHO, the B-L' distance is determined by the three factors: (1) steric effects, in the case of 4-20 mostly related to the $\mathrm{B}-\mathrm{R} / \mathrm{R}^{\prime}$ bond lengths (as they are longer, approach to the boron atom is easier), (2) substituent electronic effects influencing boron's p-orbital occupancy and (3) net attractive forces. Thus, the B- $\mathrm{L}^{\prime}$ distance is longer when one or both heteroatoms are nitrogen, and shorter for $\mathrm{R} / \mathrm{R}^{\prime}=\mathrm{H}, \mathrm{F}, \mathrm{Cl}$ and $\mathrm{P}$. No such regularity was found for the more nucleophilic $\mathrm{Cl}^{-}$. When $\mathrm{R} / \mathrm{R}^{\prime}=$ constant, the $\mathrm{B}-\mathrm{L}^{\prime}$ distances are generally longer when $\mathrm{L}=$ carbene and shorter when $\mathrm{L}=\mathrm{S}(\mathrm{O}) \mathrm{Me}_{2}$.

We have to keep in mind that the total binding enthalpies/ energies are not determined only by the magnitude of cationligand interaction energy. There is another factor that 
influences $\Delta H \mathrm{~s} / \Delta E \mathrm{~s}$ : the energy that has to be spent to deform the two interacting molecules from their equilibrium geometry to that they have in a complex. Therefore, predictions and rationalizations of $\Delta H \mathrm{~s} / \Delta E \mathrm{~s}$ must consider both $\Delta E_{\mathrm{int}}$ and $\Delta E_{\mathrm{def}}$. For example, 29 ( $\mathrm{L}=2$,6-lutidine) interacts more strongly with $\mathrm{NH}_{3}$ than any of the carbene-stabilized cations 26-28, but its $\mathrm{NH}_{3}$ affinity is the weakest because this cation has to undergo a significant conformational change in order to bind the $\mathrm{L}^{\prime}$.

With a few exceptions, major contribution to complex stabilization comes from electrostatic interactions (43-48\% when $\mathrm{L}=\mathrm{NH}_{3}$ and $\mathrm{HCHO} ; 55-60 \%$ when $\mathrm{L}=\mathrm{Cl}^{-}$), next come orbital interactions (35-45\% when $\mathrm{L}=\mathrm{NH}_{3}$ and $\mathrm{HCHO} ; 33-39 \%$ when $\mathrm{L}=\mathrm{Cl}^{-}$), while dispersion forces provide the smallest attraction (9-15\% when $\mathrm{L}=\mathrm{NH}_{3}$ and $\mathrm{HCHO}$; 7-9\% when $\mathrm{L}=$ $\mathrm{Cl}^{-}$). Four HCHO-complexes, derived from 24 and 26-28, in which $\mathrm{HCHO}$ is found at a large distance from boron atom, should be considered as being of electrostatic-dispersion type.

\section{Acknowledgements}

This work was supported by the Ministry of Education, Science and Technological Development of the Republic of Serbia (Grant No. 172020).

\section{References}

1 P. Kölle and H. Nöth, Chem. Rev., 1985, 85, 399-418.

2 (a) W. E. Piers, S. C. Bourke and K. D. Conroy, Angew. Chem., Int. Ed., 2005, 44, 5016-5036; (b) T. S. de Vries, A. Prokofjevs and E. Vedejs, Chem. Rev., 2012, 112, 4246-4282.

3 (a) S. E. Denmark and Y. Ueki, Organometallics, 2013, 32, 6631-6634; (b) J. Chen, R. A. Lalancette and F. Jäkle, Chem. Commun., 2013, 49, 4893-4895; (c) P. Eisenberger, A. M. Bailey and C. M. Crudden, J. Am. Chem. Soc., 2012, 134, 17384-17387; (d) A. Prokofjevs, A. Boussonnière, L. Li, H. Bonin, E. Lacôte, D. P. Curran and E. Vedejs, J. Am. Chem. Soc., 2012, 134, 12281-12288; (e) J. M. Farrell, J. A. Hatnean and D. W. Stephan, J. Am. Chem. Soc., 2012, 134, 15728-15731; $(f)$ E. J. Corey, Angew. Chem., Int. Ed., 2009, 48, 2100-2117.

4 (a) J. R. Lawson, E. R. Clark, I. A. Cade, S. A. Solomon and M. J. Ingleson, Angew. Chem., Int. Ed., 2013, 52, 7518-7522; (b) V. Bagutski, A. Del Grosso, J. A. Carrillo, I. A. Cade, M. D. Helm, J. R. Lawson, P. J. Singleton, S. A. Solomon, T. Marcelli and M. J. Ingleson, J. Am. Chem. Soc., 2013, 135, 474-487; (c) S. A. Solomon, A. Del Grosso, E. R. Clark, V. Bagutski, J. J. W. McDouall and M. J. Ingleson, Organometallics, 2012, 31, 1908-1916.

5 A. Prokofjevs, PhD Dissertation, University of Michigan, 2013. 6 J. A. Plumley and J. D. Evanseck, J. Phys. Chem. A, 2009, 113, 5985-5992.

7 E. R. Clark, A. Del Grosso and M. J. Ingleson, Chem.-Eur. J., 2013, 19, 2462-2466.

8 W. F. Schneider, C. K. Narula, H. Nöth and B. E. Bursten, Inorg. Chem., 1991, 30, 3919-3927.

9 A. Del Grosso, R. G. Pitchard, C. A. Muryn and M. J. Ingleson, Organometallics, 2010, 29, 241-249.
10 J. A. Plumley and J. D. Evanseck, J. Phys. Chem. A, 2007, 111, 13472-13483.

11 Y. Zhao and D. G. Truhlar, Theor. Chem. Acc., 2008, 120, 215-241.

12 J. B. Foresman and A. Frisch, Exploring Chemistry with Electronic Structure Methods, Gaussian, Inc., 1996.

13 J. A. Plumley and J. D. Evanseck, J. Chem. Theory Comput., 2008, 4, 1249-1253.

14 T. H. Dunning Jr, J. Chem. Phys., 1989, 90, 1007-1024.

15 C. Møller and M. S. Plesset, Phys. Rev., 1934, 46, 618-622.

16 M. J. Frisch, G. W. Trucks, H. B. Schlegel, G. E. Scuseria, M. A. Robb, J. R. Cheeseman, G. Scalmani, V. Barone, B. Mennucci, G. A. Petersson, H. Nakatsuji, M. Caricato, X. Li, H. P. Hratchian, A. F. Izmaylov, J. Bloino, G. Zheng, J. L. Sonnenberg, M. Hada, M. Ehara, K. Toyota, R. Fukuda, J. Hasegawa, M. Ishida, T. Nakajima, Y. Honda, O. Kitao, H. Nakai, T. Vreven, J. A. Montgomery Jr, J. E. Peralta, F. Ogliaro, M. Bearpark, J. J. Heyd, E. Brothers, K. N. Kudin, V. N. Staroverov, T. Keith, R. Kobayashi, J. Normand, K. Raghavachari, A. Rendell, J. C. Burant, S. S. Iyengar, J. Tomasi, M. Cossi, N. Rega, J. M. Millam, M. Klene, J. E. Knox, J. B. Cross, V. Bakken, C. Adamo, J. Jaramillo, R. Gomperts, R. E. Stratmann, O. Yazyev, A. J. Austin, R. Cammi, C. Pomelli, J. W. Ochterski, R. L. Martin, K. Morokuma, V. G. Zakrzewski, G. A. Voth, P. Salvador, J. J. Dannenberg, S. Dapprich, A. D. Daniels, O. Farkas, J. B. Foresman, J. V. Ortiz, J. Cioslowski and D. J. Fox, Gaussian 09 (Revision D.01), Gaussian, Inc., Wallingford CT, 2013.

17 S. F. Boys and F. Bernardi, Mol. Phys., 1970, 19, 553-566.

18 P. Su and H. Li, J. Chem. Phys., 2009, 131, 014102.

19 M. W. Schmidt, K. K. Baldridge, J. A. Boatz, S. T. Elbert, M. S. Gordon, J. H. Jensen, S. Koseki, N. Matsunaga, K. A. Nguyen, S. J. Su, T. L. Windus, M. Dupuis and J. A. Montgomery Jr, J. Comput. Chem., 1993, 14, 1347-1363. 20 (a) K. Kitaura and K. Morokuma, Int. J. Quantum Chem., 1976, 10, 325-340; (b) K. Morokuma, Acc. Chem. Res., 1977, 10, 294-300.

21 G. te Velde, F. M. Bickelhaupt, E. J. Baerends, C. Fronseca Guerra, S. J. A. Van Gisbergen, J. G. Snijders and T. Ziegler, J. Comput. Chem., 2001, 22, 931-967.

22 (a) E. D. Glendening, J. K. Badenhoop, A. E. Reed, J. E. Carpenter, J. A. Bohmann, C. M. Morales, C. R. Landis and F. Weinhold, NBO 6.0, Theoretical Chemistry Institute, University of Wisconsin, Madison, WI, 2013; (b) E. D. Glendening, C. R. Landis and F. Weinhold, Wiley Interdiscip. Rev.: Comput. Mol. Sci., 2012, 2, 1-42; (c) F. Weinhold and C. R. Landis, in Discovering Chemistry with Natural Bond Orbitals, John Wiley \& Sons, Inc., 2012.

23 J. Tomasi, B. Mennucci and R. Cammi, Chem. Rev., 2005, 105, 2999-3093.

24 In few cases only, lengths of B-heteroatom bonds remain the same.

25 This binding enthalpy was estimated as $-55.6 \mathrm{kcal} \mathrm{mol}^{-1}$ in ref. $2 b$ and 5 , at the M06-2X/6-311++G(3df,2p)//M06-2X/6$31+\mathrm{G}(\mathrm{d}, \mathrm{p})$ level.

26 L. R. Thorne, R. D. Suenram and F. J. Lovas, J. Chem. Phys., 1983, 78, 167-171. 